\title{
Projeto Eratóstenes Brasil: autonomia docente em atividades experimentais de Astronomia ${ }^{+* 1,2}$
}

\author{
Rodolfo Langhi ${ }^{3}$ \\ Departamento de Física - UNESP \\ Campus Bauru \\ Bauru - SP
}

\section{Resumo}

Resultados de pesquisas apontam para o uso das atividades experimentais no ensino de Ciências como uma das estratégias mais eficientes para despertar o interesse e a dedicação do aluno. Uma das importantes considerações sobre as atividades experimentais é a de que não há contribuição efetiva na utilização de kits com roteiros prontos, procedimentos fechados e mensuração de resultados experimentais esperados, uma vez que impede a autonomia do professor e do aluno no processo de ensino-aprendizagem. Especificamente sobre a Educação em Astronomia, as investigações mostram a importância de se levar em conta a componente observacional e prática desta ciência. É nesta linha que nossa questão de investigação foi estruturada: quais elementos subsidiam a construção da autonomia docente na elaboração e execução de atividades experimentais de maneira a contribuir efetivamente no ensino de Astronomia? Desenvolvemos esta pesquisa no contexto do Projeto Eratóstenes Brasil, por meio da análise dos discursos de um grupo de professores participantes deste projeto desde 2010. Nossos resultados revelam a predominância de uma prática

\footnotetext{
${ }^{+}$Brazilian Eratosthenes Project: autonomy of teachers in experimental activities of Astronomy

* Recebido: setembro de 2016.

Aceito: dezembro de 2016.
}

1 Apoio: CNPq; PROEX/UNESP; CEX/PREAE/UFMS; Polo Astronômico Casimiro Montenegro Filho (programa de fomento do PTI C\&T/FPTI-BR); Observatório Didático de Astronomia "Lionel José Andriatto" da UNESP; Fundunesp; IPMet UNESP (Centro de Meteorologia de Bauru); COMED/SAB (Comissão de Ensino e Divulgação da Sociedade Astronômica Brasileira); OBA (Olimpíada Brasileira de Astronomia e Astronáutica).

2 Nota: Parte deste artigo foi publicado em forma de capítulo de livro em LONGHINI, M. D. (org.). Ensino de astronomia na escola: concepções, ideias e práticas. Campinas: Átomo, 2014.

3 E-mail: prof.langhi@gmail.com 
voltada para um modelo formativo engessado numa abordagem essencialmente conteudista e sob a racionalidade técnica, com poucos elementos contribuintes à construção da autonomia do trabalho docente. Por outro lado, uma análise do histórico do Projeto Eratóstenes e das atividades desenvolvidas por alguns de seus participantes sob modelos formativos com abordagens mais reflexistas e críticas indicam potencialidades com relação ao desenvolvimento de elementos que possam capacitar esses profissionais a exercerem com autonomia a sua profissão, ao elaborar e aplicar atividades experimentais não estruturadas no ensino interdisciplinar de Astronomia.

Palavras-chave: Educação em Astronomia; Formação de professores; Atividades experimentais; Autonomia docente; Análise de Discurso; Projeto Eratóstenes Brasil.

\begin{abstract}
Research results point to the use of experimental activities in Science Education as one of the most efficient strategies to arouse interest and dedication of the students. One of the important considerations about the experimental activities is that there is no effective contribution to the use of kits with ready scripts, closed procedures and measurement of expected experimental results. This limits the autonomy of the teachers and students in the teaching-learning process. Specifically on Astronomy Education, the researches show the importance of considering the observational component and practice of this science. Then, our research question was structured: which elements subsidize the construction of teacher autonomy in the development and implementation of experimental activities in order to effectively contribute to the teaching of Astronomy? We developed this research in the contexto of Brazilian Eratosthenes Project, through a discourse analysis of a group of teachers participating in this project since 2010. Our results reveal the predominance of a training model cast in an approach extremely focused on the content and under the technical rationality, with few elements contributing to the construction the autonomy of teaching. On the other hand, a historical analysis of Eratosthenes Project and the activities developed by some of the participants indicate potential regarding the development of elements that can enable these professionals to exercise independently their profession, to develop and implemente experimental activities unstructured in the interdisciplinary teaching of Astronomy.
\end{abstract}


Keywords: Astronomy education; Teacher training; Experimental activities; Teaching autonomy; Discourse Analysis; Brazilian Eratosthenes Project.

\section{Introdução: o Projeto Eratóstenes Brasil}

Há mais de 2000 anos, um grego chamado Eratóstenes, funcionário da biblioteca de Alexandria, mediu engenhosamente as dimensões do planeta Terra, utilizando noções básicas de Trigonometria e Astronomia, comparando as disposições das sombras de determinados objetos em duas cidades diferentes. Desde 2010, as escolas brasileiras e seus professores e alunos da Educação Básica são convidados a participar do Projeto Eratóstenes Brasil, cujas atividades consistem em reproduzir este experimento com sistemática semelhante à de Eratóstenes. Com grande importância histórica para a Ciência, graças a Eratóstenes, este experimento também pode promover rica experiência social e interdisciplinar para professores e alunos de diversos estados brasileiros e de outros países, uma vez que a utilização das Tecnologias de Informação e Comunicação (TIC) se faz presente, devido à grande distância requerida entre as escolas que trabalham como parceiras na aquisição das medidas.

Desse modo, o Projeto Eratóstenes possibilita aplicar ações à distância de episódios formativos para professores visando a construção de sua autonomia para o ensino de alguns tópicos de Astronomia fundamental por meio do estabelecimento de relações sociais entre escolas localizadas no território nacional e internacional. Utilizando as TIC, ao planejarem e executarem, em conjunto, atividades experimentais, que abordem aspectos da História e Filosofia da Ciência e a interdisciplinaridade da Astronomia, fundamentam-se nas atividades de medição do raio terrestre efetuada por Eratóstenes.

Os objetivos específicos do Projeto Eratóstenes Brasil são fundamentados em resultados de pesquisas na área de Educação em Astronomia conforme levantamento efetuado por Langhi, Pedrozo Junior e Martins (2012):

- Envolver professores, alunos e escolas do Brasil e de outros países em atividades didáticas colaborativas, sob um contexto comum histórico-filosófico (do grego Eratóstenes), a fim de produzir um resultado final único do valor do raio terrestre, a partir de cada uma de suas medições;

- Resgatar recortes de momentos importantes da História e Filosofia da Ciência, por meio da prática docente em sala de aula e fora dela, fomentando discussões e debates sobre temas fundamentais de Astronomia;

- Contribuir para a interdisciplinaridade da Astronomia com Geometria, História, Geografia, Literatura, Matemática, Física, Artes, Filosofia;

- Motivar o interesse pela Ciência, divulgando seus aspectos sociais, históricos e filosóficos, mediante o estudo do experimento de Eratóstenes; 
- Utilizar as TIC (Tecnologias da Informação e Comunicação) no ensino, em atividades didático-pedagógicas e na socialização de resultados, mediante o contato direto entre escolas distantes entre si, de uma mesma língua ou não;

- Oportunizar ações episódicas à distância de formação continuada sobre conteúdos e temas de Astronomia fundamental para professores participantes;

- Abordar conteúdos de Astronomia geralmente não trabalhados durante a formação inicial de professores, visando suprir esta falha específica em sua formação, apesar de os PCN (Parâmetros Curriculares Nacionais) sugerirem este ensino na educação básica;

- Fornecer subsídios para a autonomia docente concernente à criação, elaboração e execução de atividades experimentais (semiestruturadas) relacionadas ao objetivo de medir o raio da Terra, usando procedimentos semelhantes aos que Eratóstenes utilizou há mais de dois mil anos;

- Abordar, em sala de aula, temas de Astronomia raros no ensino, tais como a descrição da geometria da incidência dos raios do Sol na Terra, em diferentes latitudes; a abordagem histórica de como a circunferência da Terra foi medida pela primeira vez, há milhares de anos; a determinação do momento real do meio dia solar da localidade onde se encontra o aluno; a execução de medidas angulares dos raios solares em relação à vertical do local; o cálculo do raio da Terra com materiais de relativa simplicidade; a existência (ou não) de sombra ao meiodia; o movimento aparente dos astros; principais elementos da esfera celeste.

Este trabalho justifica-se em razão do fato de os resultados das pesquisas na área de Educação em Astronomia apontarem para a existência de uma grande difusão de concepções de senso comum (concepções alternativas) referentes aos fenômenos astronômicos, conforme Nardi (1989), Camino (1995), Barros (1997) e Langhi e Nardi (2007a), de falhas durante a formação do professor em conteúdos básicos de Astronomia, conforme Bretones (1999) e Maluf (2000), e de erros conceituais de Astronomia em livros didáticos, conforme Pretto (1985), Canalle, Trevisan e Lattari (1997), Trevisan et al. (1997) e Langhi e Nardi (2007a). Por isso, alguns destes temas podem ser trabalhados durante o Projeto Eratóstenes Brasil, tais como a forma da Terra, o campo gravitacional, as estações do ano, os solstícios e equinócios, o movimento aparente da esfera celeste, as características de corpos astronômicos, a determinação dos pontos cardeais, o Sol a pino, o meridiano celeste, entre outros.

A interdisciplinaridade do tema do projeto também é um fator que justifica a sua execução, haja vista o grau da relação da Astronomia com os demais conteúdos e áreas de estudo, tais como História, Artes, Matemática, Geometria, Informática, Literatura, Física, Geografia, Ciências, Filosofia, conforme exemplificado com a atividade prática sugerida em Longhini, Silvestre e Vieira (2010). Segundo Tignanelli (1998), estes temas são claramente indissociáveis, o que é previsto na proposta das atividades que podem ser desenvolvidas. Os documentos oficiais nacionais para a educação básica, tais como os PCN, sugerem o ensino de conteúdos de Astronomia, como os abordados pela ação formativa do Projeto Eratóstenes Brasil (BRA- 
SIL, 1997 e 1998). Além disso, o projeto fornece subsídios para uma formação cidadã (BRASIL, 1997), por meio das relações interpessoais à distância, em torno de um tema comum escolar, ocorridas nas comunicações tecnologicamente possíveis entre as escolas participantes (alunos e professores) e outros órgãos de ensino não formal de Astronomia, tais como observatórios, planetários, museus, centros de ciências e clubes de astronomia.

A fim de contextualizar nossa pesquisa, apresentamos, a seguir, um breve histórico do trabalho de Eratóstenes, as origens do Projeto Eratóstenes Brasil (o qual abarca o tripé ensino, pesquisa e extensão), a fundamentação teórica da pesquisa e a nossa questão principal de investigação. Posteriormente, este artigo explica as atividades propostas, a natureza dos dados constituídos, os encaminhamentos metodológicos para a análise destes dados e os principais resultados encontrados.

\section{Origens históricas: Eratóstenes}

Não há nenhuma obra original do próprio Eratóstenes descrevendo o seu método de medição da Terra. A fonte mais antiga sobre seu trabalho é de Cleomedes, na obra Teoria das revoluções dos corpos celestes, do início de nossa era (DRABKIN, 1943; LOPES, 2001). Arquimedes e Aristóteles já haviam estimado, anteriormente, um valor para o diâmetro de nosso planeta, mas o valor que Eratóstenes encontrou, posteriormente, passou a ser usado como referência. Esse personagem histórico ( $275 \mathrm{aC}-194 \mathrm{aC}$ ) nasceu em Siene, antiga cidade grega, localizada no país que hoje conhecemos por Líbia. Estudou em Atenas e passou a morar em Alexandria, onde atuou como responsável pela parte do Museu da famosa biblioteca que havia ali (LOPES, 2001). Atuou de modo célebre nas áreas do que hoje denominamos de Matemática, Astronomia e Geografia, conseguindo determinar o raio da Terra, usando regras geométricas e matemáticas relativamente simples (BOCZKO, 1984; MOURÃO, 1987; LASKY, 2000; ZEILIK, 2003).

Segundo Lopes (2001), Eratóstenes partiu das seguintes hipóteses: a) Siene ficava ao sul de Alexandria e, portanto, ambas ficavam no mesmo meridiano do globo terrestre; b) a distância entre as duas cidades era de 5.000 estádios (unidade de medida da época que pode equivaler a 157,5 metros); c) Siene se localizava, exatamente, em um local onde o Sol ficava a pino, ao meio-dia, na data da entrada da estação do verão e, portanto, uma haste vertical não projetava sombra no chão neste instante; d) porém, em Alexandria, nessa mesma data e horário, uma haste vertical projetava uma pequena sombra.

Se a Terra fosse plana, as duas hastes iguais em diferentes locais projetariam uma sombra de mesmo comprimento no mesmo horário e data. Porém, sendo a Terra esférica, as hastes perpendiculares à superfície circular da Terra produziram sombras de diferentes tamanhos, pois estariam a ângulos diferentes em relação aos raios luminosos paralelos do Sol. Eratóstenes constatou que o ângulo da sombra com a haste vertical em Siene era zero, pois não 
havia sombra no chão. Por outro lado, naquele mesmo instante, ele sabia que o ângulo da sombra com a haste vertical em Alexandria era de 1/50 de uma circunferência completa, ou seja, $1 / 50$ de $360^{\circ}\left(1 / 50\right.$ de $360^{\circ}$ vale, aproximadamente, $\left.7^{\circ}\right)$.

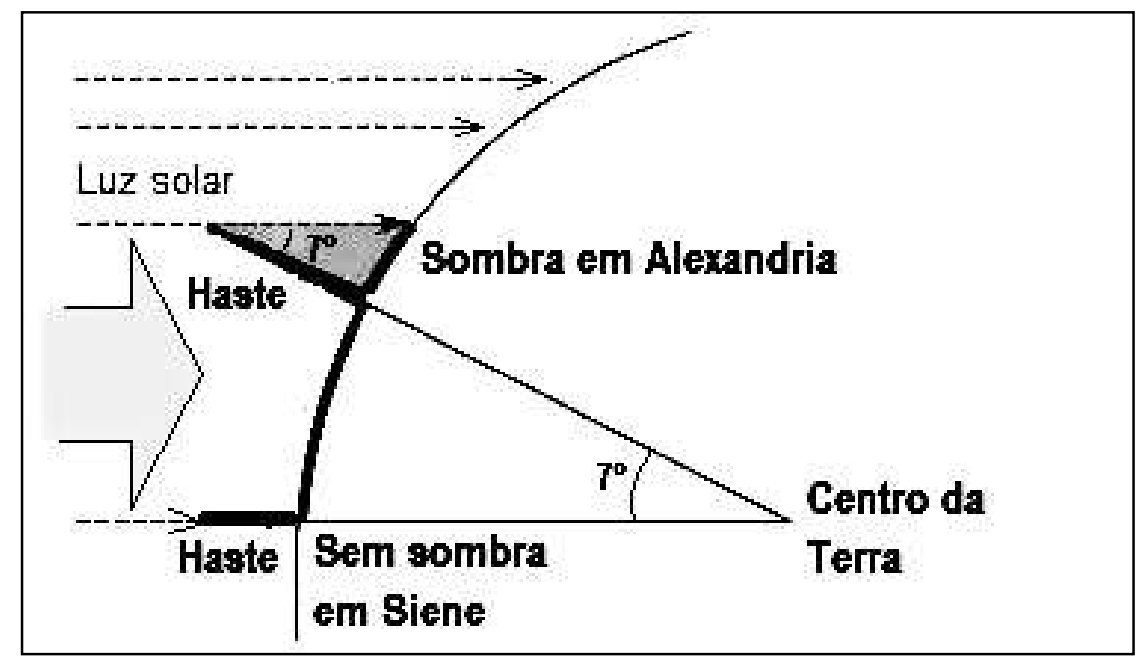

Fig. 1 -Eratóstenes conhecia o comprimento do arco de circunferência entre as duas cidades e também o ângulo formado entre elas, o que lhe permitiu o cálculo do tamanho da Terra (Fonte: adaptado de Bekeris, 2011).

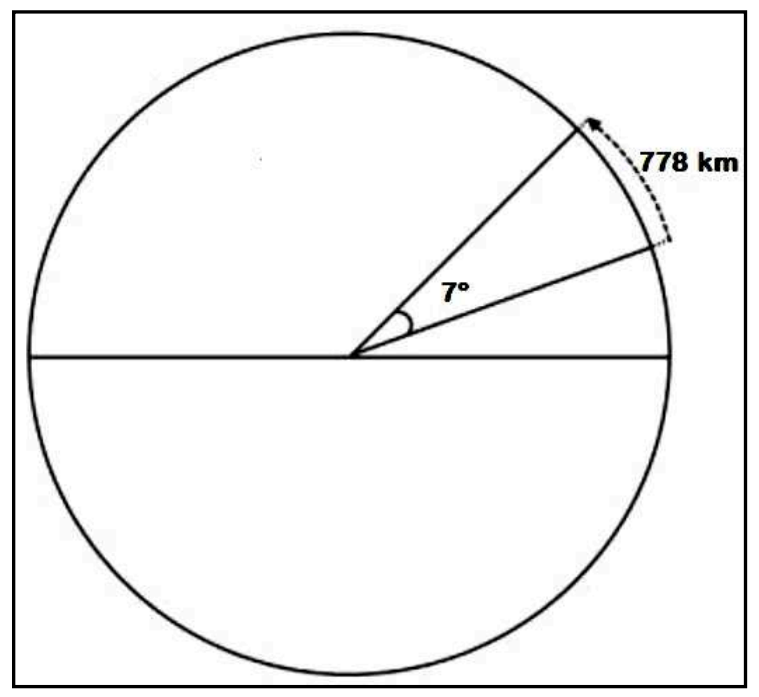

Fig. 2 - Raciocinando como Eratóstenes: a distância entre duas cidades é de $778 \mathrm{~km}$; o ângulo entre elas é cerca de $7^{\circ}$; se em $7^{\circ}$ há $778 \mathrm{~km}$, teremos em toda a volta de $360^{\circ}$, cerca de 40 mil quilômetros, que é, aproximadamente, o valor do comprimento da circunferência da Terra (Fonte: o autor, 2012). 
Desse modo, ele descobriu que entre Siene e Alexandria havia um arco de circunferência com a medida de 1/50 de uma volta completa na Terra. Uma regra de três simples poderia ser então usada para calcular o comprimento da circunferência do planeta. Se a distância entre essas cidades era de 5.000 estádios e correspondia a 1/50 de uma volta completa, então, a circunferência total de nosso planeta seria 50 vezes maior do que a distância entre estas duas cidades: 50 x $5.000=250.000$ estádios.

Segundo Lopes (2001), outros autores da área de História da Ciência citam 252.000 estádios como o valor encontrado por Eratóstenes. Também há dúvidas sobre o uso de poços ou de gnômons. Além disso, não há consenso com relação ao comprimento exato de um estádio, em metros. Em geral, assume-se o valor de 157,5 metros para um estádio (DILLER, 1949). Neste caso, o valor encontrado por Eratóstenes, para o comprimento da circunferência da Terra, seria de $39.375 \mathrm{~km}$. A medida atual é de $39.940 \mathrm{~km}$ para a circunferência do planeta, considerando o raio polar da Terra de $6.356,75 \mathrm{~km}$; o raio médio, porém, é de $6.371 \mathrm{~km}$, valor usado para o Projeto Eratóstenes.

Controvérsias à parte, concordamos com Engels (1985), quando afirma que a real contribuição de Eratóstenes talvez tenha sido o feito em si, pois, nas culturas antigas, não há registro de alguém que tenha tentado calcular as dimensões de nosso planeta com tanta precisão e nem sequer havia concordância de que a Terra era esférica.

\section{Fundamentação}

A importância de abordagens da História e Filosofia da Ciência como fios condutores para o ensino é amplamente contemplada na literatura de pesquisadores da área (MATTHEWS, 1994; PÉREZ, 2005; QUINTANILLA; IZQUIERDO; ADÚRIZ-BRAVO, 2005; GATTI; NARDI, 2009). E a Astronomia apresenta adequadas oportunidades neste sentido, pois seus episódios históricos estão repletos de exemplos contendo revoluções científicas, modelos de pensamentos e construção do conhecimento científico, tal como o caso de Eratóstenes. Assim, há uma crescente preocupação em aumentar o debate sobre o papel da Astronomia introdutória nas instituições formadoras de professores, conforme Bretones (1999), a fim de aproximar a Astronomia do ensino formal escolar, numa tentativa de aprimorar a formação dos professores e dos estudantes. Porém, mesmo que sua formação inicial não dê conta de todos os conteúdos desta natureza (BRETONES, 1999; MALUF, 2000), deve-se pensar na busca de ações de formação continuada (ou, no mínimo, episódios formativos para professores em exercício) que levem em conta a Educação em Astronomia e que sejam adequados às reais necessidades formativas dos docentes participantes.

De fato, a formação deficiente do professor em Astronomia lhe traz algumas consequências com relação à atuação docente em sala de aula, uma vez que a sua educação formal não lhe garantiu uma abordagem desses saberes disciplinares (LANGHI, 2004; LANGHI; 
NARDI, 2007). Algumas destas consequências são as dificuldades em ensinar/aprender conteúdos de Astronomia e a propagação de erros conceituais, concepções alternativas, mitos e crenças sobre fenômenos astronômicos (LANGHI, 2004, 2005; LANGHI; NARDI, 2007).

Por isso, destacamos a importância da atuação contextualizada de instituições tais como universidades, escolas, observatórios, planetários, clubes de astronomia e museus para o ensino deste tema, porém reconhecemos que há o desafio ainda a ser considerado referente ao estudo das possíveis relações entre estes estabelecimentos e iniciativas, visando o avanço da Educação em Astronomia. Essas articulações, conforme Langhi (2009), atuariam em um movimento contrário à atual dispersão das suas atividades, as quais se encontram pulverizadas em seus locais quase que isolados do contexto nacional, apresentando suas divulgações apenas em âmbito regional. Por exemplo, associações e clubes de astronomia, planetários e observatórios executam suas ações de divulgação e ensino, geralmente, sem socializar seus resultados nacionalmente, ou deixam de promover atividades de âmbito conjunto e nacional, sem envolver as escolas e a formação de professores em suas regiões; ou mesmo que haja professores ativos em ações dessa natureza, os resultados de suas atividades não são compartilhados.

Portanto, considerando a problemática acima apontada, o Projeto Eratóstenes Brasil envolve o estabelecimento de relações, principalmente, entre escolas brasileiras (além de clubes de Astronomia, planetários, centros de ciências e outras instâncias não formais de ensino), por meio de uma atividade didática realizada, preferencialmente, de modo simultâneo e conjunto em todo o país (e outros países), mediante a utilização das TIC no ensino e do intercâmbio de experiências e ideias, sob o modelo formativo dialógico-reflexivo (ZEICHNER, 1993; CONTRERAS, 2002), em torno da construção, execução e análise de um experimento semelhante ao que Eratóstenes usou há mais de 2.000 anos (BOCZKO, 1984; MOURÃO, 1987; LASKY, 2000; ZEILIK, 2003). No entanto, pesquisas na área de Ensino de Ciências apontam que apenas uma pequena minoria dos professores realiza atividades experimentais com seus alunos (SANTOS; PIASSI; FERREIRA, 2004). De fato, segundo Raboni (2002), as ações práticas se apresentam no ideário dos professores e são valorizadas, mas quase ausentes nas aulas.

Mesmo assim, a importância do trabalho com atividades práticas na Educação Básica e seu uso como um instrumento problematizador e investigativo (sem roteiros rígidos e respostas prontas) é, praticamente, consenso na literatura da área de Pesquisa em Ensino de Ciências, como mostram os estudos de Hodson (1994), Moraes (1998), Barolli (1998), Gioppo, Scheffer e Neves (1998), Borges (2002), Araújo e Abib (2003). Por isso, a elaboração da atividade experimental deste projeto não é embasada em roteiros fechados e inflexíveis, que não conferem oportunidades de intervenção e/ou modificação (ARAÚJO; ABIB, 2003), nem presume a confecção de kits prontos (GIOPPO; SCHEFFER; NEVES, 1998), mas leva-se em conta os seguintes princípios:

- Associar as atividades experimentais criadas pelos professores a questões de ordem ambiental, social, tecnológica e científica, a fim de formar cidadãos conscientes de sua condição como habitantes do planeta onde vivem (DAMÁSIO; STEFFANI, 2007); 
- Não maximizar a importância de memorizações de equações e conjunto de códigos de Física e Astronomia, alheias às suas experiências cotidianas (HECKLER; SARAIVA; OLIVEIRA FILHO, 2007);

- Utilizar materiais de baixo custo e de fácil obtenção, na elaboração do experimento, e minimizar o espaço e o tempo extracurricular usado no seu planejamento, visando incentivar o trabalho com atividades práticas no ensino (SANTOS; PIASSI; FERREIRA, 2004);

- Criar oportunidades de interações dialógicas entre os alunos e o professor, discutindo diferentes pontos de vista, propondo estratégias de ação, manipulando instrumentos, reformulando o experimento, elaborando hipóteses, prevendo resultados, confrontando previsões com resultados experimentais, e permitindo o estudo dos fenômenos (MARINELI; PACCA, 2006);

- Potencializar, por meio dessas atividades de investigação, o engajamento e a motivação dos estudantes, permitindo a superação das deficiências de atividades práticas tradicionais e puramente demonstrativas, fazendo com que os estudantes tenham um papel mais ativo e autônomo no seu processo de aprendizagem (BORGES; BORGES; VAZ, 2005);

- Mostrar ao professor participante que ele tem autonomia e competência para construir seu próprio artefato experimental para realizar as medidas do projeto, ou mesmo para reconstruir quaisquer modelos iniciais que lhes são apresentados, usando seu pensamento reflexivo e a adaptabilidade dos modelos básicos propostos (SHEN; CONFREY, 2007);

- Demonstrar que o computador e outras tecnologias são ferramentas auxiliares importantes no processo de ensino/aprendizagem, mas não substituem as realizações experimentais (BARBOSA; CARVALHAES; COSTA, 2006);

- Levar o professor, ao preparar suas atividades práticas, a exercer uma atitude autônoma e crítica ao analisar com cuidado suas possibilidades, levando em conta o importante papel delas no ensino da Astronomia, o qual abrange, dentre outros aspectos, contemplar, conforme Langhi (2009): observações sistemáticas do céu noturno e diurno; interdisciplinaridade; consideração das concepções alternativas dos alunos; contextualização e cotidianidade; questões sociais locais e mundiais; transposição didática adequada; inclusão social (portadores de necessidades especiais); abordagem CTSA (Ciência, Tecnologia, Sociedade, Ambiente); aspectos da HFC (História e Filosofia da Ciência); utilização das TIC (Tecnologias da Informação e Comunicação); uso da RPA (Resolução de Problemas Abertos); abordagem ACE (Aprendizagem Centrada em Eventos); divulgação e popularização da Astronomia como cultura perante a comunidade local.

Um levantamento bibliográfico realizado por Machado e Langhi (2013) revelou a necessidade de maior dedicação das investigações sobre os conceitos da autonomia docente e a formação de professores aplicados ao ensino formal e não formal da Astronomia. O estudo destes autores mostra que a produção bibliográfica nacional num período de cinco anos (2008 a 2013) acerca da formação de professores de Física e Ciências, quanto à sua autonomia docente e suas relações com o ensino formal e não formal da Astronomia, apresenta uma quantidade significativa de artigos publicados sem uma fundamentação teórica claramente identificada. Por 
outro lado, a análise dos 327 artigos relacionados ao tema encontrados em periódicos da área de Ensino classificados pela CAPES com qualis A e B, e dos 183 trabalhos publicados nos anais de dois eventos representativos da área, o SNEF (Simpósio Nacional de Ensino de Física) e o EPEF (Encontro de Pesquisa em Ensino de Física), revelam a recorrência do uso da fundamentação de Giroux (1997) e Contreras (2002) como referenciais dos conceitos da autonomia de professores.

Para Contreras (2002), a autonomia é uma prática social, permeando situações, e ele nos alerta contra a autonomia relativa, ilusória, e aparente. Segundo este autor, a autonomia profissional possui diferentes significados, pois suas concepções definem-se em função de três modelos de profissionalidade docente: especialista técnico, profissional reflexivo, intelectual crítico, conforme sintetizado na tabela 1.

Contreras (2002) aponta que, ultimamente, percebeu-se uma perda da autonomia da parte do professor por causa da racionalidade técnica, da demasiada ênfase em conteúdos e do aumento da burocratização, que o fez ficar sem controle de suas próprias tarefas. Assim, no campo da educação, a racionalidade técnica, segundo o autor, não encontra aplicação na grande parte do conhecimento pedagógico, e é senso comum achar que basta aplicar soluções já existentes para os problemas que devem surgir durante o ensino, ou que basta saber conteúdos para ser um "bom professor".

Tabela 1: Diferentes concepções de autonomia profissional, segundo Contreras (2002) e suas possíveis relações com os modelos de formação de professores (adaptado de Langhi e Nardi, 2012).

\begin{tabular}{|c|c|c|c|}
\hline $\begin{array}{l}\text { Modelos de pro- } \\
\text { fissionalidade do- } \\
\text { cente } \\
\end{array}$ & Especialista técnico & Profissional reflexivo & Intelectual crítico \\
\hline $\begin{array}{l}\text { Concepção de au- } \\
\text { tonomia profissio- } \\
\text { nal segundo Con- } \\
\text { treras }(\mathbf{2 0 0 2})\end{array}$ & $\begin{array}{l}\text { Autonomia como status } \\
\text { ou como atributo. Autori- } \\
\text { dade unilateral. Autono- } \\
\text { mia ilusória: dependência } \\
\text { de diretrizes técnicas, in- } \\
\text { sensibilidade perante os } \\
\text { dilemas educacionais, in- } \\
\text { capacidade de resposta } \\
\text { criativa diante a situações } \\
\text { educativas complexas. }\end{array}$ & $\begin{array}{l}\text { Autonomia como respon- } \\
\text { sabilidade moral própria, } \\
\text { levando em consideração } \\
\text { os diferentes pontos de } \\
\text { vista. Equilíbrio entre a } \\
\text { independência de juízo e } \\
\text { a responsabilidade social. } \\
\text { Capacidade para resolver } \\
\text { criativamente as situações } \\
\text { complexas do ensino e } \\
\text { para a realização prática } \\
\text { das pretensões educati- } \\
\text { vas. }\end{array}$ & $\begin{array}{l}\text { Autonomia como emanci- } \\
\text { pação: liberação profissi- } \\
\text { onal e social das opres- } \\
\text { sões. Superação das dis- } \\
\text { torções ideológicas. } \\
\text { Consciência crítica. Auto- } \\
\text { nomia como processo co- } \\
\text { letivo (configuração dis- } \\
\text { cursiva de um objetivo } \\
\text { comum), dirigido à trans- } \\
\text { formação das condições } \\
\text { institucionais do ensino. }\end{array}$ \\
\hline $\begin{array}{l}\text { Modelos de for- } \\
\text { mação de profes- } \\
\text { sores }\end{array}$ & $\begin{array}{c}\text { Tecnicista } \\
\text { Conteudista }\end{array}$ & $\begin{array}{c}\text { Reflexista } \\
\text { Humanista }\end{array}$ & Ativista \\
\hline
\end{tabular}

Assim, Giroux (1997) e Contreras (2002) deixam margem para afirmarmos que a autonomia docente é construída a partir da superação dos modelos de formação de professores 
sob uma abordagem tecnicista e conteudista, partindo para uma formação mais reflexista e humanista, mas a reflexão crítica do professor deve ir além de um limite humanista e individual, e seguir na direção de um intelectual crítico e transformador a partir da coletividade. Este modelo formativo ativista pressupõe que a reflexão dos professores não permanece no campo técnico ou prático, mas assume um compromisso social, ético e político, sendo os professores motivados a agir politicamente, promovendo mudanças ao passo que atuam autonomamente.

Neste sentido, objetivamos, neste estudo, compreender os limites e possibilidades da aplicação de atividades experimentais didáticas no tocante à autonomia docente, visando responder o seguinte questionamento: quais elementos subsidiam a construção da autonomia docente na elaboração e execução de experimentos didáticos de maneira a contribuir no ensino de Astronomia?

Assim, fundamentado nos princípios norteadores acima, desenvolvemos a pesquisa no contexto do Projeto Eratóstenes Brasil, iniciado em 2010. Salientamos, contudo, que projetos semelhantes foram realizados anteriormente no Brasil e no mundo. Por exemplo, Bozic e Ducloy (2008) relatam que foi a partir de 1995 que o número de escolas e universidades participantes em projetos Eratóstenes internacionais aumentou consideravelmente, com o primeiro convite enviado para alunos medirem a sombra de uma haste vertical ao meio-dia durante o equinócio de março daquele ano. Pereira (2006) e Pereira et al. (2006) narram experiências didáticas com a medida da Terra, fundamentadas em Eratóstenes, envolvendo a participação de algumas escolas brasileiras e instituições não formais em 2003, 2004 e 2005. Em 2009, uma ação conjunta entre Brasil, Argentina e Uruguai buscou abordar conceitos sobre Astronomia durante a observação sistemática do equinócio de março, incluindo o uso de gnômons e de métodos semelhantes aos de Eratóstenes (CAMINO et al., 2009).

O Projeto Eratóstenes original, ao qual o Brasil se afiliou em 2010, teve sua origem em 2005, nos Estados Unidos, no WYP Eratosthenes Project, durante o Ano Mundial da Física (WYP World Year of Physics), servindo de modelo para demais países. A Argentina passou a coordenar anualmente o projeto na América do Sul, por meio do Departamento de Física da Facultad de Ciencias Exactas y Naturales de la Universidad de Buenos Aires (Argentina), o Laboratorio Pierre Auger, da Universidad Tecnológica Nacional Regional Mendoza (Argentina) e a Asociación Física Argentina (BEKERIS et al., 2011). Assim, em 2009, a partir de um convite originado da comissão organizadora argentina do Projeto Eratóstenes da América do Sul, mediante o coordenador da Olimpíada Brasileira de Astronomia e Astronáutica, durante a Assembleia Geral da IAU (International Astronomical Union), nasceu o Projeto Eratóstenes Brasil, tendo sua primeira participação em 2010, com a coordenação nacional a partir da Universidade Federal de Mato Grosso do Sul. A partir de 2013, o projeto passou a ter sua coordenação nacional desde a UNESP campus Bauru (esta mudança de universidade está ligada à alteração de contratação profissional do docente coordenador do projeto) e desde 2015 o projeto 
está inserido na Comissão de Ensino e Divulgação da Sociedade Astronômica Brasileira (CO$\mathrm{MED} / \mathrm{SAB})$.

Referências adicionais e produções bibliográficas sobre o Projeto Eratóstenes e semelhantes podem ser encontradas em: Pereira (2006), Pereira et al. (2006), Bozic e Ducloy (2008), Camino et al. (2009), Bekeris et al. (2011), Almeida e Langhi (2011), Almeida e Langhi (2011a), Ferreira e Henrique (2011), Santos et al. (2012), Casarin et al. (2012), Nunes (2012), Langhi e Machado (2013), Langhi e Vilaça (2013), Langhi, Scalvi e Vilaça (2013) e Langhi (2014).

\section{Descrição das atividades desenvolvidas no projeto}

O Projeto Eratóstenes Brasil disponibiliza aos participantes informações e textos auxiliares e norteadores sobre a execução das atividades experimentais, sem, contudo, fornecer um roteiro rígido e fechado, a fim de favorecer a criatividade e a autonomia dos professores participantes ao participarem do planejamento e a execução de experimentos semiestruturados. Trata-se de uma ação de abrangência nacional, envolvendo alunos e professores do Ensino Fundamental e Médio do Brasil (e de outros países adjacentes), em atividades de socialização e motivação ao aprendizado da Ciência, por meio da utilização das tecnologias de informação e comunicação (TIC), centralizadas e disponíveis em sua homepage (PEB, 2016): <http://sites.google.com/site/projetoerato>.

O que se mede de forma direta é, principalmente, o comprimento da sombra de uma haste vertical aprumada em relação ao piso horizontal ou base nivelada. Na Astronomia, esta haste recebe o nome de gnômon. Os dados de duas escolas bem distantes permitem calcular o ângulo que há entre elas na superfície curva da Terra. Assim como fez Eratóstenes, este ângulo é usado para calcular o comprimento da circunferência da Terra e, consequentemente, o raio do planeta.

As duas escolas que trabalharão juntas podem estabelecer contato entre si, antecipadamente, a fim de discutirem ideias para a elaboração do gnômon, combinarem a data e horário da medição, métodos para cálculos etc. As escolas parceiras devem estar a não menos do que $400 \mathrm{~km}$ de distância entre si. As datas para as medidas estão compreendidas em duas semanas, por volta do equinócio de primavera de cada ano (setembro). As escolas podem efetuar suas medidas por mais de um dia, desde que estejam dentro deste intervalo.

A medida deve ser realizada exatamente no instante do meio-dia solar. Mas este horário difere em cada localidade distinta. Além disso, nem sempre esse momento coincide com o meio-dia do mostrador do relógio, mas, sim, quando o Sol cruza a metade do céu, imaginado como uma enorme cúpula. Há uma linha imaginária, ligando os pontos cardeais Sul e Norte, passando pelo ponto mais alto do céu. Esta linha divide o céu em duas partes iguais e é chamada de meridiano celeste local. Quando o Sol cruza o meridiano local, dizemos que ele está em trânsito pelo meridiano, e representa o exato momento em que o período claro do dia de 24 horas está pela metade. 


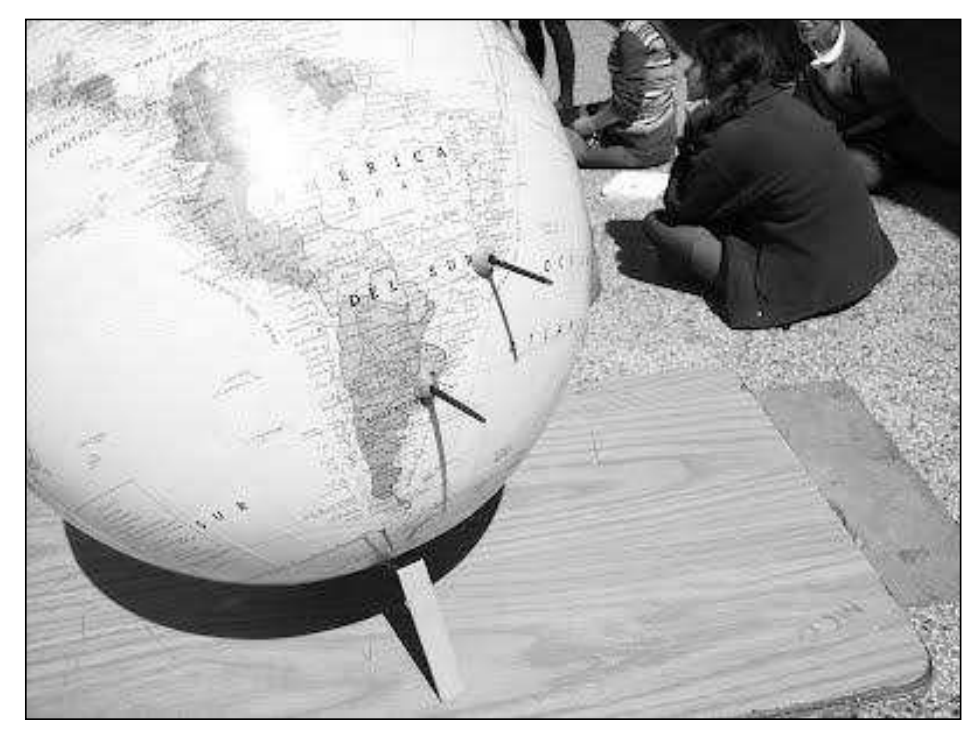

Fig. 3 - Duas hastes verticais (perpendiculares à superfície do planeta) projetam sombras de diferentes comprimentos no mesmo horário porque a superfície da Terra é curva (Fonte: Bekeris et al., 2012, s/p).

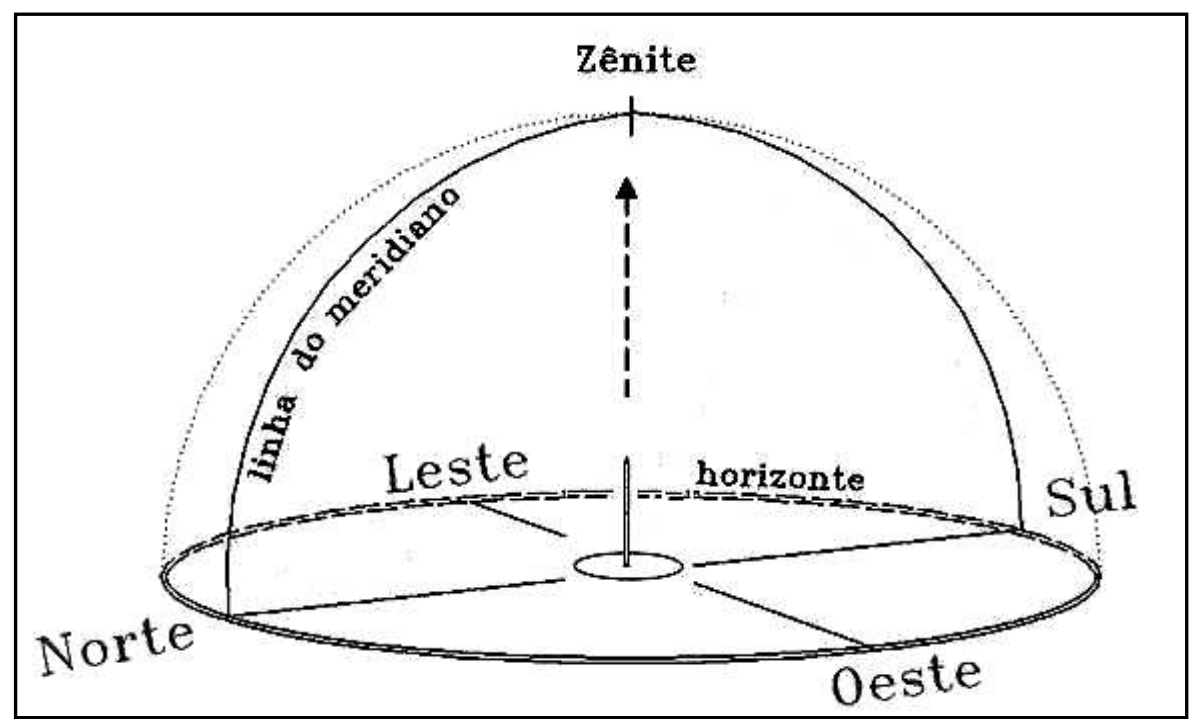

Fig. 4 - Imaginando a linha do meridiano celeste local: trace uma linha no céu, partindo do ponto cardeal Norte, passando pelo zênite (ponto diretamente acima de sua cabeça ou do gnômon) e terminando no ponto cardeal Sul (Fonte: Langhi, 2011, p. 26).

Como o meio-dia solar não corresponde ao meio-dia do mostrador do relógio, é necessário usarmos outro método para sabermos o instante exato em que isto se dá: simplesmente, basta acompanhar a sombra até que ela atinja o comprimento mínimo daquele dia. Antes do meio-dia, a sombra da haste (gnômon) vai diminuindo de tamanho até um instante de tempo em que ela passa a aumentar. Este instante é o meio-dia solar, quando, então o Sol cruza o 
meridiano. Registra-se a medida do comprimento da sombra, a menor daquele dia, e anotada a hora marcada pelo relógio. É importante lembrar que o horário deve ser antecipadamente acertado de acordo com a hora oficial de Brasília, segundo uma referência confiável, tal como o relógio atômico do Observatório Nacional (ON, 2016).

Embora alguns materiais didáticos escolares e outras fontes continuem a afirmar que ao meio-dia o Sol fica a pino no céu, sem sombra projetada no chão, e muitas pessoas ainda apresentem esta concepção alternativa, essa simples atividade mostra que nem sempre isto ocorre (LANGHI; NARDI, 2007). Apenas os moradores das cidades localizadas entre as linhas dos trópicos (Capricórnio e Câncer) é que experimentarão o Sol a pino em somente dois dias do ano. Em especial, os moradores das cidades localizadas na linha do Equador verão o Sol a pino nas datas dos dois equinócios de primavera e outono. Observadores localizados exatamente na linha do trópico terão o Sol a pino apenas em um dia do ano, na data do solstício de verão (entrada desta estação), cujo caso foi justamente o de Eratóstenes. Por outro lado, habitantes situados entre os trópicos e os polos terrestres nunca terão Sol a pino. Portanto, nem sempre (ou melhor, quase nunca), os habitantes da Terra experimentam Sol a pino, ao meiodia, diferente do que muitas pessoas acreditam e do que muitos livros didáticos já afirmaram (LANGHI, 2011).

Também interessa-nos a medida do comprimento do gnômon, desde a sua ponta superior até o ponto onde ele se apoia na base em que a sombra está sendo projetada. Conhecendo o comprimento da haste e o da sombra, temos um triângulo retângulo, cujos ângulos podemos calcular com trigonometria simples. Ambas as medidas referem-se aos catetos do triângulo, os quais, usando a relação trigonométrica da tangente, fornecem o ângulo dos raios solares daquele local e naquele instante (a tangente do ângulo é igual ao comprimento da sombra dividido pelo tamanho do gnômon). Cada escola obtém um ângulo diferente, pois o valor depende da latitude. Subtraindo-se os dois ângulos obtidos pelas escolas, descobre-se qual é o ângulo formado entre estas duas cidades na superfície do globo terrestre.

Sabendo-se a distância (arco de circunferência do globo terrestre) entre as duas escolas e também o ângulo entre elas, é possível calcular o comprimento da circunferência da Terra por meio de "regra de três" simples: o comprimento do arco de circunferência entre as escolas está para o ângulo entre elas, assim como o comprimento da circunferência completa da Terra está para $360^{\circ}$. Cada par de escolas tem autonomia para discutir suas medições e executar os cálculos juntos, via internet, ou outro meio das TIC que julgarem mais apropriado. Os resultados finais são, então, submetidos ao Projeto Eratóstenes, via homepage, e uma média final é calculada pela coordenação do projeto.

No entanto, este projeto tem a intenção de superar o ato de simplesmente alcançar um resultado médio único e numérico, a saber, o raio da Terra. Como explicitado na fundamentação, pretende-se atingir questões educacionais, melhorias nas metodologias do trabalho docente e em técnicas de ensino, abranger a interdisciplinaridade da Astronomia e a relevância de seus conteúdos no âmbito escolar, histórico e filosófico, num modelo formativo docente, que não o 
tradicional (LANGHI, 2009). Pode ser um espaço para o diálogo, a reflexão, a criação (autoria) e a reconstrução de modelos e aparatos experimentais previamente propostos e para a resolução de problematizações apresentadas pelo professor, por meio de discussões coletivas e da construção de habilidades e competências (BORGES; BORGES; VAZ, 2005; MARINELI; PACCA, 2006; BARBOSA; CARVALHAES; COSTA, 2006; DAMÁSIO; STEFFANI, 2007; HECKLER; SARAIVA; OLIVEIRA FILHO, 2007; SHEN; CONFREY, 2007; LANGHI, 2009).

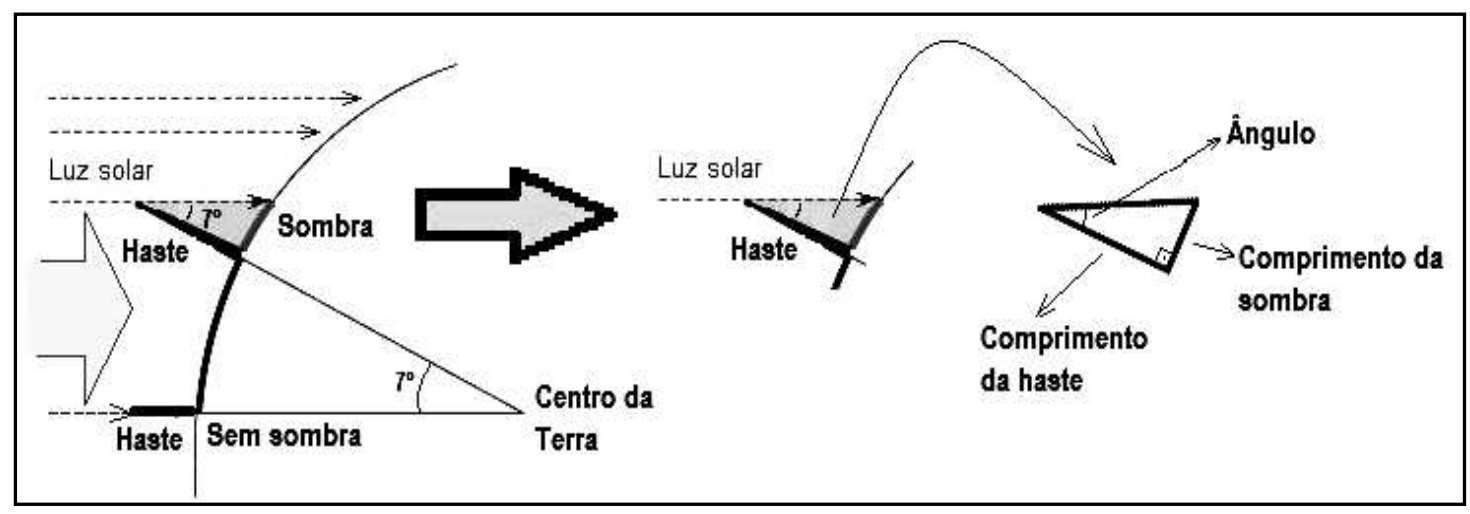

Fig. 5 - A haste (gnômon) é um cateto de um triângulo retângulo e a sombra é o outro cateto. A partir destas medidas, o uso da relação trigonométrica da tangente permite calcular o ângulo que os raios solares fazem com a haste. Se duas escolas distantes entre si conhecem estes ângulos, a diferença entre eles resulta no ângulo que há entre as duas cidades (ver Fig. 2). No caso de Eratóstenes, um dos ângulos valia zero, pois não havia sombra projetada (ver Fig. 1). (Fonte: o autor, 2012).

\section{Proposta de um aparato experimental flexível}

A fim de diferenciar a aplicação dessa atividade, sob um viés contrário ao da memorização e do ensino meramente conteudista, com roteiros experimentais fechados, optamos pela proposta de construção e utilização de um material que sirva como um modelo inicial básico, flexível e mutável pelos professores participantes do projeto. De fato, de acordo com Camino (2004), esses tipos de "modelos concretos" funcionam como ferramentas para a aprendizagem de Astronomia, desde que seguidos alguns critérios ao elaborá-los. Sua natureza, como um "modelo transformável", revela a flexibilidade em permitir alterações a partir das reflexões e autonomia dos professores, potencializando um espaço ao diálogo coletivo entre os alunos ou outros participantes (RABONI, 2002; SHEN; CONFREY, 2007).

Por isso, apresenta-se ao participante uma proposta de construção de um gnômon com materiais simples e de baixo custo, contudo, de modo algum deve ser entendido como receita pronta, muito menos como um modelo obrigatório de construção pelos participantes do projeto. Como sugestão de materiais a ser providenciados, embora nem todos talvez sejam usados, 
aponta-se: prumo e "nível de bolha" (usados em construção civil), trena, régua, esquadros, lápis novo para servir de gnômon, lápis para anotações, fita adesiva, relógio, tachinhas, papel para anotações, papelão, cartolina e borracha.

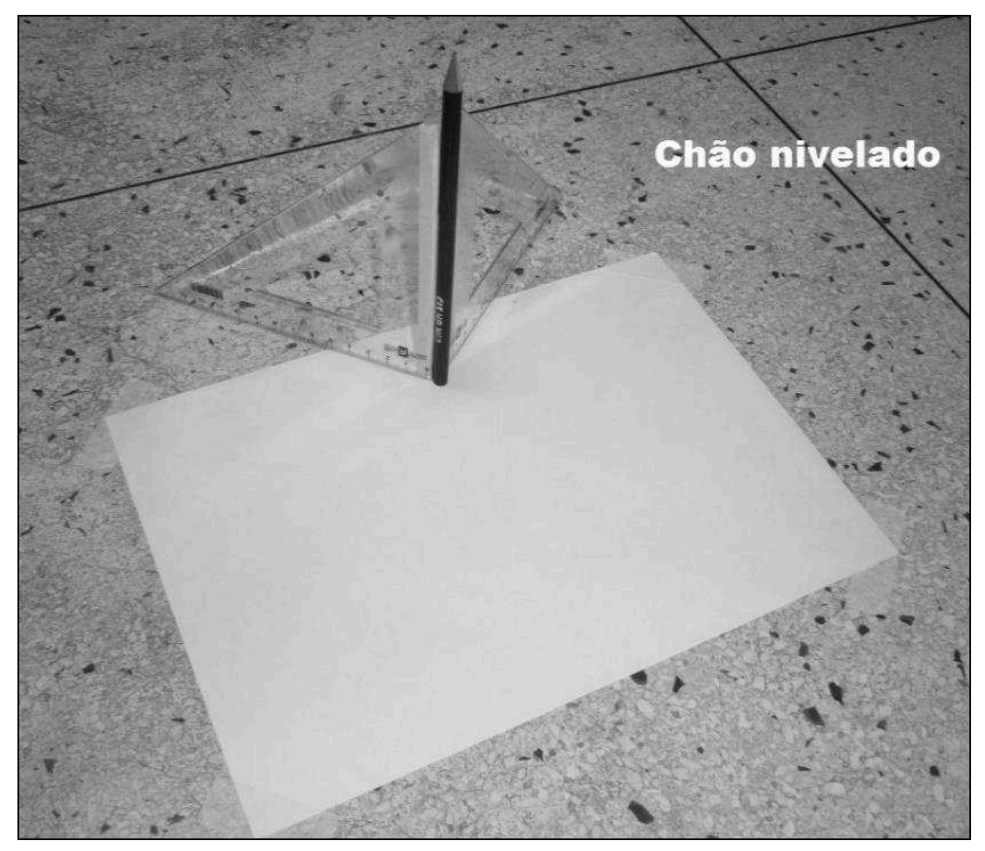

Fig. 6 - Um lápis apoiado no papel e fixo por dois esquadros pode servir de gnômon e fornecer os dados necessários para a participação no Projeto Eratóstenes (Fonte: o autor, 2012).

Um lápis novo serve de gnômon. No entanto, deve-se garantir a sua perpendicularidade em relação ao solo, ou seja, ele deve ficar, perfeitamente, na posição vertical em relação a uma superfície plana e nivelada. Normalmente, as quadras de esporte das escolas costumam ser niveladas, mas é recomendável o uso de um "nível de bolha" para constatar o nível do chão. $\mathrm{Na}$ parte da manhã, uma folha de papel sulfite ou uma cartolina pode ser fixada com fitas adesivas no piso plano onde se fará a medida. É preciso escolher um local onde não haverá sombra de prédios ou árvores. Dois esquadros escolares podem ser anexados ao lápis com fita adesiva, a fim de apoiá-lo na posição vertical. Este conjunto é posicionado sobre o papel no chão e o lápis produzirá uma sombra. Recomenda-se fixar, também, o conjunto com fita adesiva sobre o papel, impedindo que ele se desloque com o vento forte ou por outro incidente qualquer.

Antes do meio-dia, o grupo de alunos pode acompanhar a sombra do lápis, que deverá, aos poucos, diminuir de tamanho e mudando seu ângulo com o passar do tempo. A partir das 11:30, por exemplo, os alunos fazem, de cinco em cinco minutos, uma pequena marcação na extremidade da sombra, projetada pela ponta do gnômon. Junto com a marca, deve-se escrever o horário da marcação. Esta marca indicará a posição em que a extremidade da sombra do gnômon se encontrava naquele instante. Durante estas anotações, não é tão evidente a percepção 
de que a sombra está aumentando ou diminuindo de tamanho, pois todas elas aparentemente aparecerão com as mesmas dimensões, sendo sutilmente perceptível apenas a mudança de suas direções. Esta dificuldade na visualização decorre do fato de o tamanho dela variar um milímetro ou menos a cada cinco minutos durante o período das marcações.

Embora difícil de perceber no ato das marcações, a sombra, de fato, diminui de tamanho e atinge um comprimento mínimo em um determinado instante e, depois, a sombra passa a aumentar sua dimensão. Este instante da menor sombra é o meio-dia solar e é, justamente, esta marcação que interessa ao Projeto. Outra marcação contornando o ponto onde o lápis-gnômon está apoiado no papel facilita a medida correta do comprimento da sombra do meio-dia solar (desde o cruzamento entre o plano do papel e um eixo central imaginário ao longo do comprimento do lápis até a marcação da ponta da sombra).

O comprimento da haste (lápis-gnômon) também interessa. Com essas duas medidas, pode-se calcular o ângulo por meio da tangente do triângulo retângulo que possui como catetos: o comprimento da haste e o comprimento da sombra. Este ângulo subtraído com o ângulo que outra escola parceira encontrou resulta no ângulo entre as duas cidades. Este valor é usado para calcular a circunferência da Terra e o seu raio, tal como Eratóstenes. A esse respeito, a escola tem a opção de realizar os cálculos em conjunto com uma escola de sua escolha, ou, simplesmente, remeter as medidas do comprimento da haste e da sombra, a data e o horário na homepage do projeto. No caso da segunda opção, a própria coordenação do projeto se encarregará de realizar as parcerias de escolas, automaticamente, à medida que outros participantes vão inserindo seus dados.

No entanto, a construção do aparato experimental, para a obtenção das medidas ganha mais sentido quando ocorrem discussões e aberturas ao diálogo, além de oportunizar interações com a formação de trabalhos em grupos, sem, contudo, apresentar imediatamente a solução ou revelar previamente aos alunos o comportamento da sombra, ou ainda fornecer o aparato experimental finalizado (como já mencionado, o experimento acima refere-se a apenas uma sugestão de montagem e não deve impedir a reflexão e a construção particular do pensamento e raciocínio para resoluções de problemas da parte dos alunos ou a elaboração criativa de seu próprio experimento, diferenciando-o da sugestão apresentada pelo site do projeto).

Os professores de disciplinas diferentes podem, por exemplo, abordar, antecipadamente, questões históricas e filosóficas por trás do feito de Eratóstenes, relações trigonométricas; funcionamento das coordenadas geográficas; conceitos de raios luminosos paralelos, fontes de luz, precisão em medidas, relações entre culturas distintas e a geografia de outros locais onde escolas parceiras se inserem; termos de língua estrangeira necessários para o estabelecimento de relações à distância com outras escolas ou para a submissão das medidas na homepage argentina etc.

Posteriormente, questões e problemas podem ser levantados e apresentados à turma, as quais, talvez, incluam o desafio de procurar caminhos para a construção de um aparato que permita a medida da Terra, elaboração de tabelas de dados que precisarão levantar e registrar, 
planejamento de um roteiro de atividades que eles mesmos deverão seguir, quais procedimentos matemáticos pretendem utilizar para a solução do problema apresentado, em quais fontes de consulta confiáveis poderão obter informações a respeito etc. Para tanto, o professor responsável pelo grupo atua como um mediador na construção coletiva da solução da problemática apresentada, mas sem fornecer respostas prontas ou produtos acabados. Após as medidas efetuadas, o grupo pode, nas próximas aulas, discutir os cálculos e outros tópicos interdisciplinares, tendo Eratóstenes como fio condutor dos diálogos.

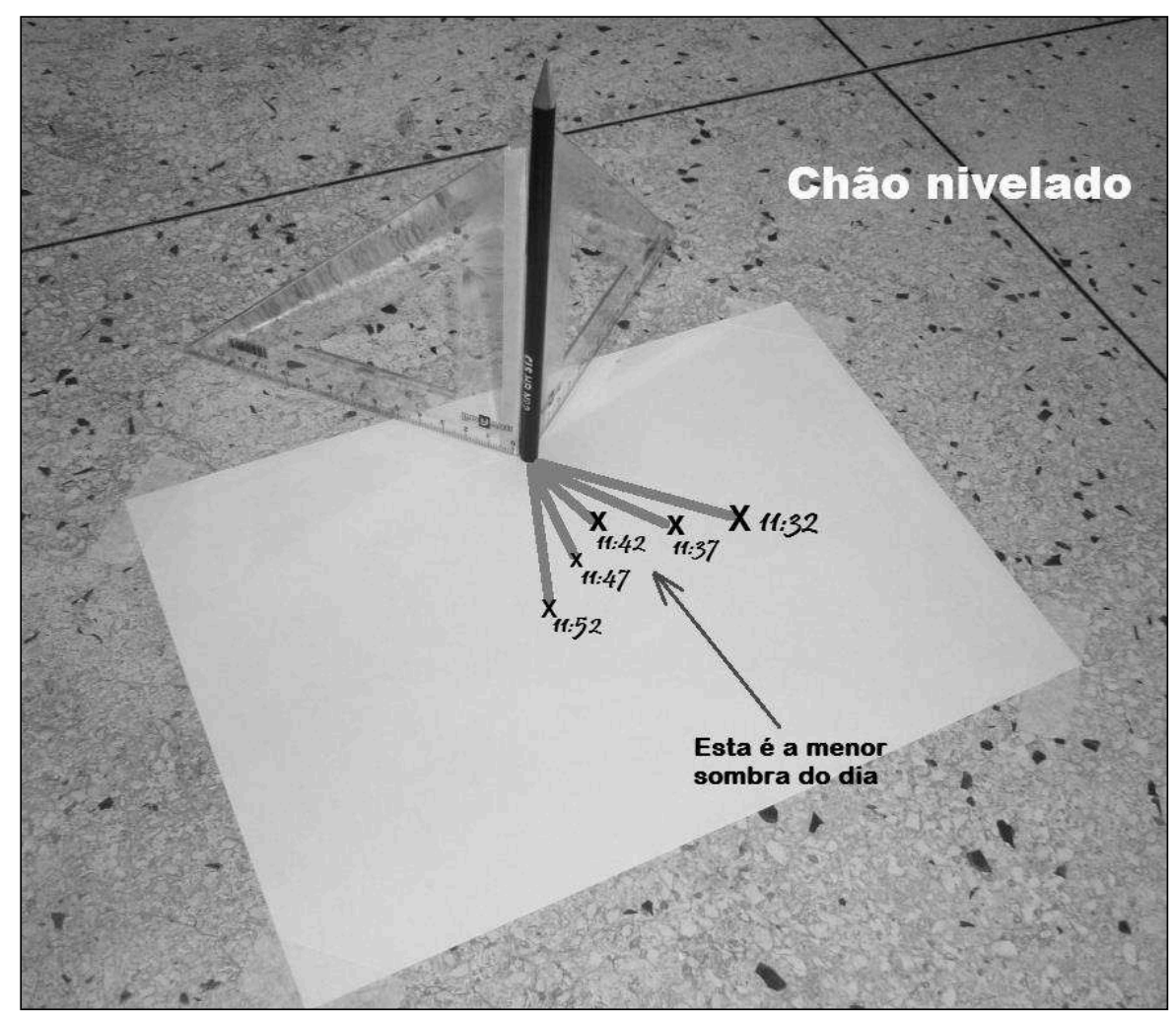

Fig. 7 - Representação artística da sombra em diferentes horários, anotados no papel. Para o projeto, interessa o comprimento do gnômon (neste caso, o lápis) e o comprimento da menor sombra do dia (ao meio-dia solar verdadeiro, o qual, nesta suposição, ocorre às 11:42 do relógio). Vale salientar que as sombras reais, marcadas a cada cinco minutos, não ficam tão distanciadas entre si, e as diferenças nos seus comprimentos não é tão perceptível como mostra a figura deste exemplo fictício (Fonte: o autor, 2012).

No ato da inscrição no Projeto Eratóstenes (antecedente a qualquer atividade acima descrita), a escola ou clube de astronomia insere, gratuitamente, na homepage oficial do projeto, as seguintes informações: nome da escola ou da instituição, país, estado, cidade, nome completo do professor responsável, telefone, e-mail, número de séries (ou anos escolares) participantes, número de alunos participantes, coordenadas geográficas locais (latitude e longitude). 
Além dessas informações obrigatórias, espera-se que os participantes discutam entre si sobre alguns dados adicionais que podem ser registrados pelos grupos participantes, talvez, no formato de ficha para anotações e organização de suas atividades: data da medição (há a possibilidade de a escola realizar várias medidas por mais de um dia), horário do meio-dia solar (hora, minuto e segundo), comprimento da haste, em centímetros (gnômon), comprimento, em centímetros, da sombra da haste no meio-dia solar (a menor sombra daquele dia) e o valor calculado do ângulo.

Para o caso de optarem por parcerias a partir de escolha própria, os grupos devem notar a importância de incluir os seguintes dados: nome da escola parceira escolhida, métodos usados para se comunicarem, distância norte-sul entre os paralelos das latitudes onde se encontram as escolas parceiras, valor do raio terrestre calculado pelas duas escolas (em quilômetros). Outras informações interessantes podem ser registradas, tais como: quantidade total de alunos e suas idades, quantidade de grupos de alunos, valores obtidos por grupo, fotos, filmagens, comentários, sugestões, relatos de experiências etc.

As sugestões acima servem para enriquecerem o trabalho docente, mas não há a obrigatoriedade em escolher uma parceria para participar do Projeto Eratóstenes. No ato da submissão das medidas efetuadas pela escola, a homepage solicita apenas quatro informações mínimas: a) comprimento do gnômon, em centímetros; b) comprimento da menor sombra do dia, em centímetros (no meio-dia solar); c) a data e d) o horário desta sombra. Esta facilidade no envio dos resultados tem motivado a inscrição de novos participantes, já que não há a obrigatoriedade de comunicações com parceiros distantes ou a execução de cálculos que, segundo relatos de alguns professores, desencorajam a inscrição da escola no Projeto Eratóstenes. Todos os participantes responsáveis (professores ou dirigentes de clubes de astronomia ou de outras instâncias não formais de ensino) recebem um certificado pela participação.

\section{Resultados do Projeto Eratóstenes}

Considerando os últimos quatro anos de participação, o Brasil foi o único país a aumentar, mesmo que sensivelmente, a quantidade de participantes, ao passo que os demais tiveram seu número reduzido (exceto em 2013). Os pares de escolas eram formados com modelos estatísticos controlados pela coordenação geral do Projeto, por meio de software apropriado, a fim de fornecer uma medida combinada, de acordo com métodos de otimização distribuídos com base nas coordenadas geográficas de todos os participantes no dia da medição. No entanto, algumas escolas usaram sua liberdade em escolher uma parceria de modo voluntário, enriquecendo, assim, a atividade.

A quantidade de inscrições difere, significativamente, da de participantes efetivos, pois, em média, pouco mais da metade dos inicialmente interessados passaram a realizar, efetivamente, as medidas (há a necessidade de estudos posteriores, a fim de compreender os motivos deste fenômeno). A tabela 2 resume quantitativamente o Projeto Eratóstenes com o destaque 
para a participação brasileira por meio do Projeto Eratóstenes Brasil (antes de 2011, as medidas eram efetuadas na semana do solstício de junho, mas atendendo a diversos pedidos provenientes das escolas, a coordenação alterou a data para setembro devido às férias escolares de inverno).

Tabela 2: Resultados do Projeto Eratóstenes, desde o início da participação brasileira. Os números, entre parênteses, mostram a quantidade de escolas participantes de cada país (Fonte: autor, 2016).

\begin{tabular}{|c|c|c|c|c|c|c|c|}
\hline & 2010 & 2011 & 2012 & 2013 & 2014 & 2015 & 2016 \\
\hline Data da medição: & 18 a $24 / 06$ & 13 a $27 / 09$ & 10 a $21 / 09$ & 14 a $24 / 09$ & 15 a $26 / 09$ & 14 a $25 / 09$ & 15 a $27 / 09$ \\
\hline Raio encontrado $(\mathbf{k m})$ : & $R=6.375 \pm 25$ & $R=6.460 \pm 70$ & $\mathrm{R}=6.430 \pm 120$ & $R=6.350 \pm 20$ & $R=6.360 \pm 20$ & $R=6.360 \pm 20$ & $R=6.360 \pm 20$ \\
\hline Pares de escolas: & 174 & 150 & 110 & 150 & 150 & 200 & 133 \\
\hline $\begin{array}{r}\text { Quantidade estimada } \\
\text { de alunos: }\end{array}$ & 15.000 & 15.000 & 12.000 & 8.400 & 6.800 & 8.000 & 6.000 \\
\hline $\begin{array}{r}\text { Total inicialmente } \\
\text { inscrito: }\end{array}$ & 460 & 310 & 282 & 390 & 415 & 353 & 267 \\
\hline $\begin{array}{r}\text { Total de participantes } \\
\text { efetivos: }\end{array}$ & 226 & 198 & 169 & 222 & 167 & 174 & 146 \\
\hline $\begin{array}{r}\text { Porcentagem de } \\
\text { participação: }\end{array}$ & $49 \%$ & $64 \%$ & $60 \%$ & $57 \%$ & $40 \%$ & $49 \%$ & $55 \%$ \\
\hline Países participantes: & $\begin{array}{l}\text { Argentina } \\
(149) \\
\text { Brasil (33) } \\
\text { Colômbia (2) } \\
\text { Cuba (4) } \\
\text { México (14) } \\
\text { Uruguai (18) } \\
\text { Venezuela (6) }\end{array}$ & $\begin{array}{l}\text { Argentina } \\
(130) \\
\text { Brasil (47) } \\
\text { Chile (1) } \\
\text { Colômbia (2) } \\
\text { México (5) } \\
\text { Peru (1) } \\
\text { Uruguai (10) } \\
\text { Venezuela (2) }\end{array}$ & $\begin{array}{l}\text { Argentina } \\
(104) \\
\text { Bolivia (1) } \\
\text { Brasil (48) } \\
\text { Espanha (2) } \\
\text { México (4) } \\
\text { Peru (3) } \\
\text { Uruguai (6) } \\
\text { Venezuela (1) }\end{array}$ & $\begin{array}{l}\text { Argentina (84) } \\
\text { Brasil (34) } \\
\text { Catalunha (1) } \\
\text { Colômbia (1) } \\
\text { Espanha (77) } \\
\text { França (1) } \\
\text { Honduras (2) } \\
\text { México (3) } \\
\text { Peru (3) } \\
\text { Uruguai (14) } \\
\text { Venezuela (2) }\end{array}$ & $\begin{array}{l}\text { Argentina (62) } \\
\text { Brasil (35) } \\
\text { Colômbia (2) } \\
\text { Espanha (37) } \\
\text { França (1) } \\
\text { Honduras (2) } \\
\text { Itália (2) } \\
\text { México (7) } \\
\text { Peru (5) } \\
\text { Portugal (2) } \\
\text { Rep. Tcheca (1) } \\
\text { România (1) } \\
\text { Uruguai (10) }\end{array}$ & $\begin{array}{l}\text { Argentina (50) } \\
\text { Brasil (45) } \\
\text { Colômbia (5) } \\
\text { Espanha (42) } \\
\text { França (1) } \\
\text { Honduras (1) } \\
\text { Itália (1) } \\
\text { Marrocos (1) } \\
\text { México (2) } \\
\text { Peru (5) } \\
\text { Portugal (1) } \\
\text { Romênia (2) } \\
\text { Uruguai (18) }\end{array}$ & $\begin{array}{l}\text { Argentina (42) } \\
\text { Brasil (33) } \\
\text { Bulgária (1) } \\
\text { Catalunha (2) } \\
\text { Colômbia (3) } \\
\text { Espanha (29) } \\
\text { França (1) } \\
\text { Galícia (1) } \\
\text { Honduras (1) } \\
\text { Irlanda (1) } \\
\text { México (2) } \\
\text { Peru (5) } \\
\text { Romênia (2) } \\
\text { Uruguai (17) }\end{array}$ \\
\hline
\end{tabular}

\section{Encaminhamentos metodológicos da pesquisa}

Visando adequar os caminhos trilhados em busca de respostas ao questionamento central, segundo os objetivos desta pesquisa, privilegiamos uma abordagem qualitativa de investigação, pois, segundo Bogdan e Biklen (1994), ser qualitativo nas pesquisas presume o interesse primário em dados ricos em pormenores descritivos relativos a pessoas, locais e conversas, ao invés do complexo tratamento estatístico. Também, para Goldenberg (2001), na pesquisa qualitativa, o pesquisador preocupa-se principalmente com o aprofundamento da compreensão de um determinado grupo social, uma organização, uma instituição, ou trajetória, enquanto que a representatividade numérica é secundária.

Em nosso caso, os dados a serem analisados foram constituídos a partir da coleta dos discursos e relatos de alguns dos professores participantes do Projeto Eratóstenes Brasil desde a sua primeira edição até o ano de 2015, com a utilização da técnica do questionário estruturado online emitido para seus e-mails (GIL, 1996; FLICK, 2009), cujas questões foram: 1) Descreva como foi a elaboração das atividades do Projeto Eratóstenes com seus alunos; 2) Descreva quais foram todas as suas dificuldades antes, durante e após a sua participação do Projeto Eratóstenes Brasil; 3) Escreva quais contribuições a participação no Projeto Eratóstenes Brasil trouxe para: a) você, b) para o seu trabalho como professor, c) para os seus alunos e d) para a sua escola; 4) 
Opcional: Fique à vontade para fornecer sugestões e críticas para a melhoria do Projeto Eratóstenes Brasil; 5) Opcional: Por favor, envie-nos fotos do grupo de alunos e professores que executaram o experimento do Projeto Eratóstenes Brasil.

Trata-se de um questionário simplificado contendo perguntas subjetivas e de certo grau de descrição e reflexão, visando a emersão de discursos subjacentes às ações dos professores. Durante a elaboração das perguntas, foram realizadas reuniões com a equipe de coordenação do projeto para discussões acerca da confiabilidade do questionário, o qual foi submetido a algumas aplicações pilotos e a um grupo de pesquisadores que mantiveram seu anonimato. Estas ações possibilitaram reformulações do questionário até que o mesmo adquirisse um grau de confiabilidade coerente aos objetivos desta pesquisa e à sua aplicação definitiva.

Exemplificamos, a seguir, alguns trechos transcritos de algumas das respostas mais significativas dos professores, identificados por $\mathrm{P} 1 \mathrm{a}$ P9, as quais representam adequadamente os resultados finais desta pesquisa. Suas repostas constituíram, assim, no corpus de dados, analisados de acordo com os objetivos e fundamentação teórica desta pesquisa segundo interpretações possibilitadas com a Análise de Discurso. Conforme Orlandi (2002), o suporte do discurso ou o meio pelo qual se concentram ou se materializam vários discursos, se dá pelo indivíduo e do grupo ao qual representa. Para a análise, Orlandi (2002) argumenta que o primeiro passo é o pesquisador elaborar uma pergunta, a qual define a forma da análise, que por sua vez define a forma do dispositivo analítico (que amoldará a prática de leitura e a interpretação). Em nosso caso, esta pergunta é a própria questão de pesquisa, e o dispositivo analítico está embasado na fundamentação apresentada neste artigo acerca da autonomia docente e sintetizado na figura 9 (encontrada juntamente com os parágrafos que comentam os resultados).

A análise destes discursos, dessa forma, possibilita ao investigador descobrir os meandros do pensamento expresso por um determinado indivíduo ou grupo social. Ela articula o linguístico com o social e se propõe a "realizar leituras críticas e reflexivas que não reduzam o discurso a análises de aspectos puramente linguísticos nem o dissolvam num trabalho histórico sobre ideologia" (BRANDÃO, 2002).

Assim, ao analisar os discursos do grupo de professores aqui investigados, levamos em conta que o texto é atravessado por posições destes sujeitos (ORLANDI, 2000), pois falam de um determinado lugar. Em um mesmo texto podemos encontrar enunciados de discursos diversos, que derivam de várias formações discursivas. As palavras simples do nosso cotidiano já chegam até nós carregadas de sentidos que não sabemos como se constituíram e que, no entanto significam em nós e para nós. No dizer há sempre um não-dizer, que pode ser interpretado de diferentes maneiras, dependendo do que o analista procura. Por outro lado, um não-dito também é passível de interpretação, ou seja, o silêncio também é discurso.

Neste sentido, o ato da leitura é o momento crítico em que se desencadeia o processo de significação (ORLANDI, 2000) e a análise do discurso não interpreta os textos que estão sendo analisados, mas sim os resultados desta análise enunciativa, buscando a compreensão do 
processo produtivo do discurso em detrimento de sua interpretação, proporcionando-nos subsídios para a identificação de elementos influentes na construção da autonomia dos professores analisados em relação à elaboração e execução de experimentos didáticos para o ensino de Astronomia no âmbito do Projeto Eratóstenes Brasil.

\section{Análise dos dados e resultados encontrados}

Alguns professores citaram títulos de livros paradidáticos de Astronomia consultados durante o projeto para o planejamento de suas aulas, indicando uma necessidade de busca por informações sobre Astronomia, cujo tema não fora contemplado durante a sua formação inicial. Porém, nem sempre as fontes de consulta eram confiáveis, pois algumas das mais citadas referem-se a homepages da internet sem critérios de escolha bem definidos: "as consultas foram feitas diretamente na internet” (P5). Segundo Orlandi (2000), nas situações em que o sujeito deixa de enunciar expressões em seu dizer, oculta-se um não-dito passível de interpretação, já que o silêncio também é discurso. Ao comentar sobre as fontes de busca de informações para suas aulas de Astronomia, os professores não citam artigos de periódicos acadêmicos que abordam aspectos da pesquisa em ensino de Astronomia, o que evidencia o desconhecimento desta produção bibliográfica.

Esta lacuna discursiva denuncia ainda a desarticulação existente entre teoria (referimonos aos resultados de pesquisas sobre ensino de ciências) e a prática (referimo-nos à prática docente), isto é, o distanciamento entre a escola e a universidade. De fato, Zeichner (1993) confirma esta dicotomia da teoria/prática quando afirma que a ideia de uma separação entre teoria e prática é uma concepção muito comum, pois muitos imaginam que a "teoria" é apresentada nas universidades durante um curso de formação inicial e a "prática" ocorre nas escolas, quando o professor supostamente aplica as teorias produzidas e aprendidas nas universidades. Estas condições afetam diretamente a construção da autonomia dos professores, pois a carência em saberes disciplinares (conteúdos a serem ensinados) reduz a sua amplitude de trabalho com o tema em sala de aula (TARDIF, 2004).

A Olimpíada Brasileira de Astronomia e Astronáutica (OBA) também foi citada como referência de avaliação do rendimento dos alunos, quanto à aprendizagem de conceitos de Astronomia: "os resultados obtidos na Olimpíada Brasileira foram significativos" (P2). De fato, os resultados anuais desta ação nacional revela uma mobilização crescente do professorado pela busca autônoma dos conhecimentos dos conteúdos acerca da Astronomia, representando um grande incentivo no aprendizado desta ciência.

Assim, a análise destes discursos permite-nos ponderar que a falta de autonomia parece estar presente quando o professor limita-se a um modelo conteudista e expositivo de ensino, em detrimento à possível pluralidade metodológica e o uso de atividades práticas em seu cotidiano escolar, não ampliando seus saberes nem superando sua impessoalidade. Conforme Contreras (2002) e segundo interpretações permitidas por esta análise discursiva, a autonomia, neste 
caso, é ilusória e o professor atua simplesmente como "especialista técnico" dentre os modelos de profissionalidade docente (ver tabela 01), uma vez que ele apresenta insensibilidade perante o dilema educacional em relação à confiança absoluta em livros didáticos, em olimpíadas e materiais denominados "educativos" ou em sites da internet não confiáveis.

Revelou-se também, nos discursos de alguns professores, uma atenção demasiada quanto aos passos de execução do experimento, os quais supostamente deveriam ser seguidos fielmente, sem espaços para discussões sobre eventuais erros ou falhas no procedimento juntamente com seus alunos: "fiz uma descrição breve dos procedimentos e encaminhamento de material para leitura" (P1); "explanei o projeto, expliquei o trabalho (...) e descrevi os passos do projeto" (P6); "gnômon ficou na vertical, a superfície de apoio ficou nivelada (...) para o Sol atingir o meridiano local" (P3); "foram usados os manuais já fornecidos pelo projeto anteriormente" (P5); "praticidade da aplicação das técnicas de medição" (P5); "levei os alunos ao pátio da escola e efetuamos as medições. Em sala fizemos os cálculos e enviamos à coordenação" (P6). Estes excertos discursivos demonstram o quanto estes professores não apresentaram uma independência significativa de diretrizes técnicas. Neste caso, os "modelos transformáveis" (CAMINO, 2004) experimentais, fornecidos pela coordenação do Projeto Eratóstenes, não foram usados com a flexibilidade esperada nem sofreu modificações.

Como aponta Orlandi (2002), há uma relação entre o já-dito e o que se está dizendo, ou seja, entre o interdiscurso e o intradiscurso. O interdiscurso é o conjunto de formulações realizadas e já esquecidas que determinam o que se diz. Assim, o intradiscurso revelador destas limitações dos professores quanto à criatividade do manuseio de atividades experimentais permite-nos relacionar com interdiscursos de uma herança histórica que remete às condições da época da década de 1960, quando projetos de renovação do ensino de Ciências avançaram no país, apresentando propostas de atividades experimentais sob a racionalidade técnica com roteiros engessados, situação educacional ainda persistente atualmente (NARDI, 2005) e evidentemente presente nos discursos destes professores investigados. Aliás, os próprios discursos não são autônomos, pois se remetem a outros discursos, onde os intradiscursos destes sujeitos estão inscritos no interdiscurso herdado da época em que os experimentos didáticos e os kits prontos eram embasados em roteiros fechados e inflexíveis, não conferindo oportunidades de intervenção e/ou modificação, cujo discurso ideológico prevalece ainda hoje em diversos materiais didáticos.

Por isso, as condições de produção dos discursos dos professores analisados acima demonstram uma excessiva preocupação em seguir de perto cada detalhe do experimento proposto, embora seu objetivo tenha sido apenas de servir como ideia inicial fornecida pela coordenação do Projeto Eratóstenes. Tendo em vista a sua insegurança ou incapacidade de criatividade em modificar o "modelo concreto" proposto (CAMINO, 2004), estes sujeitos falam de um lugar com autonomia limitada, sob uma abordagem acrítica. Mesmo oferecendo-lhes as condições de demonstrarem sua autonomia para a execução de sua atividade experimental, apresentaram uma ação docente reprodutivista. Neste âmbito de análise discursiva, portanto, na visão 
de Contreras (2002), revelou-se uma autonomia como status ou atributo, uma autonomia ilusória em que se reforça um modelo de profissionalidade docente onde o professor é um "especialista técnico", diretamente relacionado a um modelo formativo tecnicista e acrítico, sob a racionalidade técnica (ver tabela 1 e Fig. 9).

Partindo em direção ao rompimento com o modelo exclusivamente conteudista/tecnicista do trabalho docente, destacam-se discursos de professores dos quais emergem uma atuação mais humanista, dispensando o caráter totalmente impessoal, mas potencializando o diálogo coletivo entre os alunos e ele mesmo (RABONI, 2002; SHEN; CONFREY, 2007). A análise dos discursos destes sujeitos nos permite entender como os objetos simbólicos produzem sentidos, pois não há verdade oculta atrás do texto, mas há gestos de interpretação e um processo de significação (ORLANDI, 2002).

Nesta visão, identificamos, nos excertos discursivos das respostas dos professores, expressões que significam a pessoalidade, bem como o caráter humano e social da atividade experimental desenvolvida: "foi muito legal o trabalho com os alunos" (P2); "alunos que participaram das oficinas ficaram muito empolgados" (P2); "foi extremamente prazeroso para os alunos" (P2); "meus alunos mais motivados e a escola ganhou projeção" (P3); "trouxe resultados formidáveis no que se refere ao interesse pelos experimentos de física" (P5); "meus alunos ficaram encantados em saber que estavam trabalhando em conjunto com uma escola da Argentina" (P6); "para a alegria das crianças" (P9); "com atividades recreativas unidas ao conhecimento" (P9); "objetivo de despertar o interesse por Astronomia e divulgação científica” (P9); "quando conhecemos bem a ciência, em particular a física, podemos compreender toda a sua beleza e nos tornamos cativados por elas, com este intuito de divulgar de forma agradável e interessante" (P9); "amo astronomia!!!!! Consegui em dois dias fazer tantas atividades que estou felicíssima! Tirei mais [de] 1000 fotos!!!!” (P9); “jovens necessitam de atividades que despertem sua curiosidade" (P9); "pais ficaram encantados com o mural com as fotos das escolas parceiras internacionais" (P9); "reconhecimento" (P1); "interesse em participar de atividades práticas" (P1).

Algumas das unidades discursivas acima produzem uma significação sob a dimensão motivacional e indicam a componente fortemente presente da pessoalidade, pois adjetivam sua experiência vivenciada com o ensino da Astronomia por meio do Projeto Eratóstenes, fazendose valer dos seguintes elementos: legal, empolgante, prazeroso, motivador, formidável, interessante, encantamento, alegria, beleza, cativante, agradável, amar astronomia, felicidade, curiosidade, reconhecimento, participação. Tais unidades textuais reforçam os elementos motivacionais existentes em relação ao tema Astronomia, pois conforme Langhi e Martins (2014), "apesar de a literatura da área apontar com frequência que a Astronomia é considerada motivadora, não há trabalhos com fundamentação teórica sobre conceitos específicos que envolvem a motivação". Estas formações discursivas revelam a imagem dominante que os alunos e professores, enquanto sujeitos enunciadores, fazem do referente (Astronomia), ao mesmo tempo em que ocupam suas próprias posições imaginárias de satisfação pessoal (ORLANDI, 2002). 
De fato, estes excertos discursivos apontam para uma reestruturação mental que supera o intelectualismo e o conhecimento por ele mesmo, pois a compreensão do universo proporciona o desenvolvimento de aspectos exclusivos da mente humana, tais como fascínio, admiração, curiosidade, contemplação e motivação (LANGHI; NARDI, 2014). Na visão de Contreras (2002), estas enunciações estabelecem uma relação com uma autonomia cuja abordagem de modelo de profissional apresenta-se num modelo humanista, pessoal e mais reflexivo, levando em consideração os sentimentos envolvidos, seus diferentes pontos de vista e a independência de juízo, ainda que estes discursos não tenham evidenciado claramente uma responsabilidade moral própria, segundo nossa interpretação (ver tabela 1 e Fig. 9).

Conforme indicam as pesquisas sobre formação de professores, o conjunto de saberes docentes, ou corpus de conhecimentos especializados, é tão importante ao ponto de uma profissão ficar ameaçada caso não se leve em conta os seus saberes específicos (GAUTHIER et al., 1998). Por exemplo, caso se reduza o preparo pedagógico (saberes específicos ao trabalho docente) e se dê mais ênfase à formação disciplinar (saberes não específicos ao trabalho docente, mas focado demasiadamente em conteúdos), então qualquer pessoa que detenha o saber disciplinar (conteúdos a serem ensinados) poderia ter livre acesso ao ato de ensinar, segundo esta concepção. Em outras palavras, um engenheiro poderia dar aulas de Física, ou uma enfermeira poderia lecionar Biologia. Em ambos os exemplos, a profissão de Professor, o Profissional da Educação, fica ameaçada.

Por isso, a amplitude dos saberes docentes constituída pelo professor está diretamente relacionada à autonomia dele, como indicam as seguintes enunciações dos professores do nosso grupo de análise: "minhas aulas ficaram mais ricas" (P3); "professor tem que estar atento a tudo e a todos e buscar sempre atividades diversificadas para atender a grande demanda" (P9); "aumentou o número de atividades disponíveis" (P1); "oficinas; vídeos; atividades com crianças" (P9); "trouxe conhecimento para todos os envolvidos" (P6); "falei sobre a poluição luminosa" (P9); "transformar uma simples medição em uma atividade que desperte a curiosidade" (P9). Estas enunciações exemplificam outras dimensões da amplitude de saberes docentes (evidenciados durante suas aulas no âmbito do Projeto Eratóstenes Brasil), os quais não se limitam a apenas "saber conteúdos" para o ato de ensinar.

Quanto aos saberes docentes mais específicos, podemos destacar os relacionados à abordagem da História e Filosofia da Ciência no ensino: "discutimos a importância da biblioteca de Alexandria, o legado de Eratóstenes, falamos sobre alguns de seus contemporâneos (como Euclides)" (P3); “iniciamos com uma abordagem histórica” (P5); "resgate histórico proporcionado pelo projeto" (P2); “com a visita de Eratóstenes ([pessoa] com as roupas de Eratóstenes)" (P9); "descobriram a importância dos cálculos de Eratóstenes, comprovados até hoje" (P9). Estas formações discursivas, conforme Orlandi (2002), estão carregadas de significações de certo nível criativo, pois estas ações não estavam previstas na proposta inicial fornecida pelo Projeto Eratóstenes. Assim, segundo Orlandi (2000), estes sujeitos falantes superam os níveis 
de locutor (que se representa como eu no discurso) e enunciador (perspectiva que este eu constrói), e adquirem a função de autoria (função social que este eu assume enquanto produtor da ação ou da linguagem).

Neste sentido da função autor, também emergiram em seus discursos os saberes docentes relacionados à interdisciplinaridade da Astronomia: "aproxima de outras disciplinas que aparentemente poderia se pensar que não haveria nenhum diálogo" (P2); "fizemos estudos sobre vários tópicos de Astronomia" (P3); "este trabalho ajudou-me a fazer interdisciplinaridade com outras ciências como Geografia, Matemática, História e Espanhol” (P3); "atividades recreativas unidas ao conhecimento e estudo da matemática e Astronomia" (P9); "nossos parceiros falam em outro idioma" (P9).

Uma das propostas foi o incentivo do uso das TIC em que diferentes escolas, localizadas em diferentes estados e países, se comunicassem para a realização da troca de informações, dados e cálculos, embora isto não seja obrigatório no Projeto Eratóstenes. Como mostraram as análises discursivas, a utilização das TIC proporcionou uma interação cultural e social que só seria possível para poucos alunos. Entretanto, por meio do projeto, grupos relativamente grandes puderam interagir com uma mesma finalidade e propósito, mantendo esses contatos para a realização de outras atividades, oportunamente. A figura 8 ilustra algumas destas parcerias.

De fato, os discursos dos professores reforçam a importância do uso das TIC no ensino: "ainda não temos uma sala de informática com internet (...), mas quando isso acontecer, colocarei os alunos em contato direto com a escola parceira" (P6); "usei um programa abaixo, utilizando o computador" (P9); "com a tecnologia a nosso favor para uma educação, podemos ressaltar a importância deste experimento" (P9); "a informação está em tempo real, nos chega através de celulares, tablets e outros meios de comunicação" (P9); "facebook foi essencial para a divulgação também, pois a troca de fotos e experimentos foi muito boa e interativa" (P9). Portanto, a amplitude dos saberes docentes, quando não limitados apenas aos conteúdos a serem ensinados (saberes disciplinares), estabelece uma relação direta com a construção da autonomia, pois o professor supera o modelo do "especialista técnico", em direção ao "profissional reflexivo", como indica Contreras (2002), conforme sintetizado pelo dispositivo analítico apresentado na Fig. 9.

Revelando uma autonomia como responsabilidade moral própria, mas relativa, os discursos de alguns professores nos permitem inferir certa capacidade para resolver criativamente algumas situações que surgem durante o processo de ensino (CONTRERAS, 2002): "os valores obtidos eram muito imprecisos, devido às dimensões reduzidas dos gnômons" (P1); "registramos vários experimentos ao mesmo tempo com gnômons diferentes" (P3); "não só na troca de dados numéricos, mas é preciso que os professores envolvidos troque outras experiências" (P3); "este projeto é muito bom e o que o faz interessante é o fato de trabalharmos em conjunto com escolas de outros países" (P6). Embora o Projeto Eratóstenes não obrigasse o professor a compartilhar suas medidas com outras escolas, nem comentasse todos os detalhes envolvidos em 
situações imprevistas durante a atividade experimental, as formações discursivas destes professores denotam capacidade para resolver determinadas problemáticas de ensino, tais como a identificação das causas das imprecisões das medidas e a tomada de decisão própria ao compartilhar e refletir sobre sua atividade experimental de modo coletivo com outras escolas. A análise destes discursos nos permite inferir um modelo de profissionalidade docente próximo do que Contreras (2002) denomina de "profissional reflexivo", que trabalha coletivamente e leva em conta diferentes pontos de vista, não realizando a sua atividade simplesmente por obrigação, mas a assume como responsabilidade moral de cumpri-la da melhor maneira.

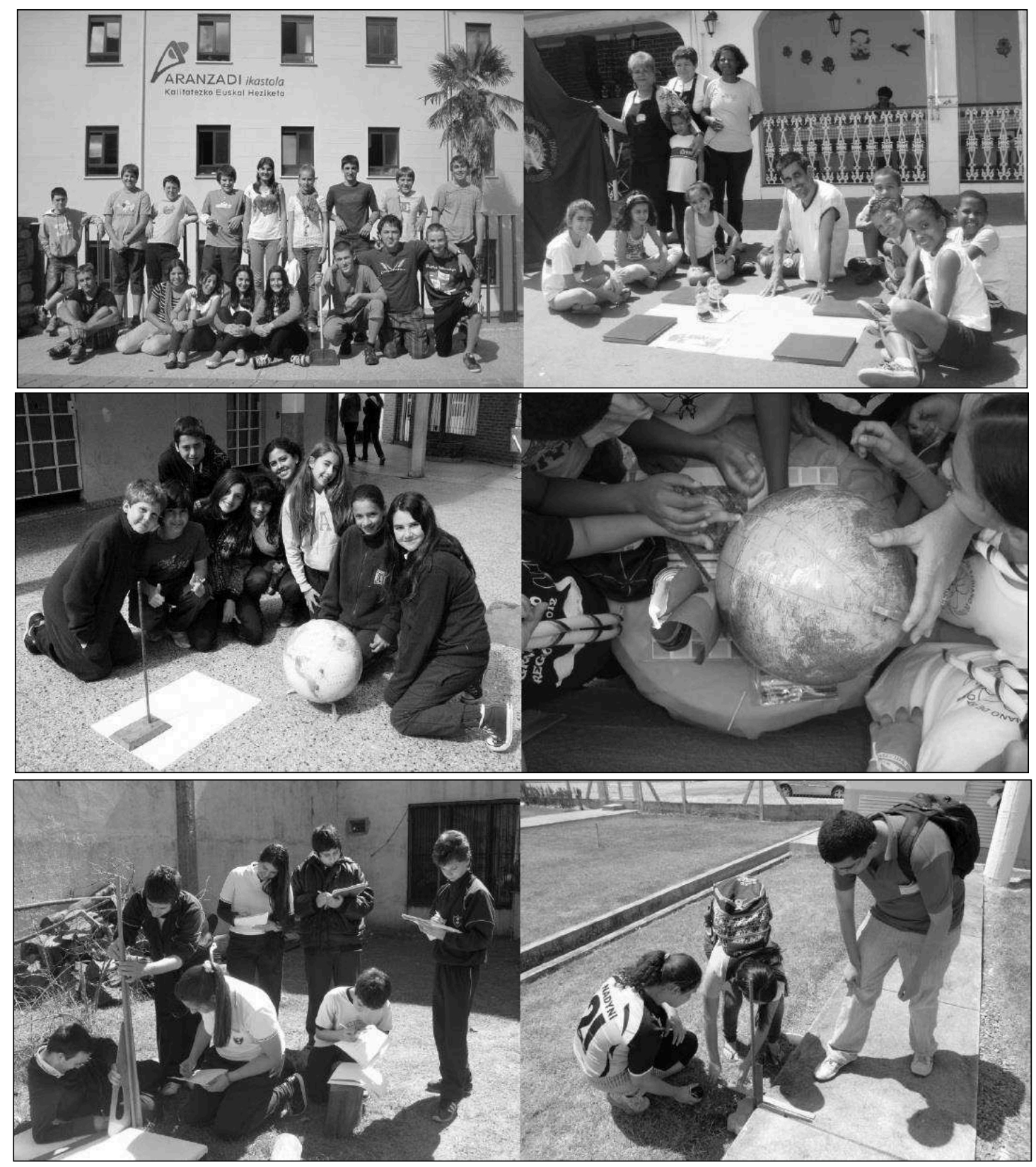

Fig. 8-Algumas fotos enviadas pelas escolas participantes. Acima à esquerda: Aranzadi Ikastola, Bergara, Guipúzcoa, Espanha. Acima à direita: Centro Educacional Nosso 
Mundo, Rio de Janeiro. Meio à esquerda: Fray Mamerto Esquiu, City Bell, Argentina. Meio à direita: Grupo Escoteiros 52, Rio de Janeiro. Abaixo à esquerda: Instituto San Cayetano, Buenos Aires, Argentina. Abaixo à direita: Itaperuna, Rio de Janeiro (Fonte: Bekeris, 2012).

Ao conjugar os verbos na primeira pessoa do plural, os discursos indicam um avanço do caráter individual para o coletivo. De fato, Zeicher (1993) mostra que a reflexão coletiva sobre a própria prática contribui para o desenvolvimento profissional. Entretanto, Giroux (1997) e Contreras (2002) vão mais longe e deixam claro que a reflexão do professor deve ir além de um limite humanista e pessoal, mas seguir na direção de um intelectual crítico e transformador - fato não emergido destes recortes discursivos (ver dispositivo analítico na figura 9).

Outras situações complexas de ordem extrínseca no ambiente de ensino foram apontadas pelos professores, sem, contudo, demonstrações de capacidades para resolvê-las criativamente (CONTRERAS, 2002): “dificuldade de mobilização no horário do meio dia solar, por ser hora do almoço" (P1); "tivemos problemas com nuvens em uma das datas" (P3); "outra dificuldade está relacionada à localização da minha escola. Estamos bem em cima do trópico de capricórnio e sofremos com as inconstâncias características do clima da região" (P6).

Pelas enunciações dos sujeitos, extrai-se significações preocupantes no que tange a elementos ligados à formação inicial do professor: "principal dificuldade foi a parte matemática, pois eu não entendo muito de geometria" (P6); "os valores obtidos estavam sob grande imprecisão" (P2).

Alguns elementos relacionados à infraestrutura do ambiente formal de ensino despontam nos discursos dos professores: "dificuldade (...) de identificação do espaço mais apropriado, devendo ser plano" (P1); "falta de apoio escolar para dar continuidade e também de permanecer na escola onde estava" (P2); "queria muito participar, mas não tive apoio na escola" (P8); "não foram observadas dificuldades. Todo o apoio foi dado pela direção da escola" (P5); "a direção sempre contribuiu" (P3); "me inscrevi, mas não tive motivação para trabalhar com os alunos" (P7); "tentei incentivar em momentos posteriores os meus alunos, mas fiquei (...) sem apoio no âmbito escolar" (P2).

Apesar de estes elementos ligados à formação docente, infraestrutura e de ordem extrínseca estarem frequentemente atrelados a problemáticas da complexidade do ensino, bastante comuns no ambiente escolar nacional, os discursos destes professores nos permitem inferir uma ação com responsabilidade moral própria, resolvendo criativamente algumas destas situações e dificuldades do trabalho docente. Segundo Contreras (2002), estes aspectos confirmam um viés do modelo de profissionalidade do "professor reflexivo" (ver tabela 01 ), com atitude mais crítica, sob a racionalidade prática, em comparação com as condições de produção dos discursos anteriormente analisados.

Pensando o professor enquanto um profissional que visa transformar sua prática e a sua realidade, encontramos em Contreras (2002) o modelo transformador do docente "intelectual crítico", cujo nível de autonomia atinge a emancipação (ver Fig. 9). Não foi o caso 
identificado pelos sujeitos de nosso grupo de análise, contudo fomos capazes de registrar alguns elementos indicadores para este caminho, pois em alguns discursos parece emergir o ensaio de uma transformação das condições locais de ensino: "montar um observatório rústico" (P2); "tenho um blog" (P2); "parceria com o Observatório Astronômico da Ufes" (P2); "culminou com a criação de um projeto que foi denominado Observando o Sol e a Lua. Onde estão incluídas diversas oficinas" (P2); “contar com o acolhimento do Planetário de Vitória” (P2); “consegui publicar um trabalho importante na área da Astronomia sobre o projeto" (P3); "apresentamos este trabalho em Brasília sobre as experiências que deram certo" (P3); "para mim trouxe um destaque especial, pois fiquei conhecido na escola como o professor que faz trabalhos diferenciados" (P6); "sessão de Cúpula e visita guiada orientada pelos Monitores do Planetário" (P9); "Projeto Maratona da Via Láctea e Projeto Observando as Estrelas" (P9); “monitorei a Observação com o uso do Telescópio” (P9); “devido a minha participação, organização e estruturação do Projeto Eratóstenes o Grupo Escoteiros do Brasil assinaram um acordo com o Planetário da Gávea" (P9).

Na visão de Orlandi (2000), os discursos podem demonstrar uma hierarquia das funções de locutor, enunciador e autor. Autor é a função que o "eu” assume enquanto produtor de linguagem (ou de uma ação, já que agir é também um discurso) e que está mais determinada pelo seu contexto sócio histórico. É como um jogo entre a liberdade (do sujeito) e a responsabilidade (do autor). Apenas falar torna-o falante, apenas dizer torna-o locutor, e só enunciar não

basta para ser autor. É preciso assumir a responsabilidade desse papel social, responsabilidade essa que é cobrada em várias dimensões e normas (ORLANDI, 2000). De fato, Contreras (2002) apresenta a autonomia como um processo social e coletivo, sendo atingida a partir de uma consciência crítica com responsabilidade.

Neste sentido, estes discursos revelam a função "autor" destes professores, com indícios de construção de uma autonomia como emancipação e como processo coletivo da parte destes professores: desejo de montar um observatório, a constituição de um blog sobre o assunto, firmar parcerias com observatórios de universidades, planetários e outras instituições, elaborar projetos de maior amplitude, publicar e apresentar trabalhos em eventos da área, estabelecimentos de outros acordos e parcerias por iniciativa própria. Nota-se a forte componente social e a importância da coletividade nestes casos, contrariamente à impessoalidade e individualidade (conforme dispositivo analítico da Fig. 9).

\section{Comentários gerais sobre os resultados}

O fato de não haver roteiros fechados e rígidos permitiu o exercício da autonomia, da liberdade e do incentivo à criatividade dos professores e alunos participantes para o planejamento de seus roteiros particulares, conforme os princípios comentados na fundamentação deste texto (ZEICHNER, 1993; CONTRERAS, 2002). Cada escola foi responsável pela decisão de 
qual material e métodos a utilizar, seguindo alguns parâmetros propostos pela comissão coordenadora do projeto. Em uma primeira análise, aparentemente, algumas escolas não levaram em consideração certas orientações para a elaboração de seu roteiro.

Analisando as imagens e fotos enviadas por várias escolas, observamos que as atividades de algumas delas não consideraram a ocorrência de erros de medições em cada método e material escolhido, e que havia a sua propagação durante os cálculos, gerando resultados relativamente diferentes dos esperados (exemplos encontrados: alguns usaram seu próprio corpo como gnômon, a haste não estava perfeitamente na vertical, o chão não era bem nivelado, confusões entre meio-dia solar e meio-dia marcado pelo relógio, cuidados com a existência de penumbra na ponta da sombra, respeito à dimensão máxima da haste, a medida da altura do gnômon não era feita desde a base onde a sombra estava projetada).

Deste modo, podemos inferir que, possivelmente, as falhas de formação de alguns desses docentes, associadas aos problemas comentados na fundamentação deste trabalho, além da omissão de leitura do material orientador disponível na homepage do projeto, podem ter contribuído para alguns destes resultados. Por outro lado, notamos certos professores participantes do projeto com notável interesse, dedicando-se para que este fosse realizado de maneira significativa para o aprendizado dos alunos. Alguns professores socializaram interessantes ideias e se mostraram prestativos em ajudar os que estavam com mais dificuldades.

Os resultados da pesquisa também apontam para oportunidades de aprimoramento e aspectos de melhoria para o próprio projeto. Acreditamos ser possível potencializar a participação de um volume maior de escolas nos próximos anos, já que o projeto tem caráter anual. Levando em conta a discrepância entre a quantidade de escolas brasileiras convidadas (mais de dez mil) e o número de escolas inscritas, e, ainda, o total de escolas que, efetivamente, enviaram suas medidas, ressaltamos a necessidade do incentivo a uma maior participação (tabela 2). Além da necessidade de uma divulgação mais ampla, há outras possíveis explicações para esse relativo baixo número de participações, conforme reveladas a partir da análise dos discursos destes diferentes professores: dificuldades na compreensão do processo de medida, excesso de informações para leitura no material fornecido pelo projeto, falta de apoio da direção e dos colegas da escola, falta de um kit ou modelo pronto do instrumento de medida a ser construído com os alunos, solicitações de um roteiro fechado com procedimento passo-a-passo, segundo a racionalidade técnica.

Mesmo que o projeto incentive a autonomia e a flexibilidade mediante a criatividade e contextualização, a maioria dos professores parecem esperar receber uma receita pronta e detalhada sobre os procedimentos da atividade experimental. Isto revela que vários professores do grupo analisado encontram-se predominantemente sob o modelo formativo conteudista e tecnicista, com baixo potencial para reflexões crítico-ativistas (ver tabela 1 e Fig. 9). Apesar de o aparato experimental constituir-se apenas como uma sugestão do Projeto Eratóstenes, este parece ter sido o molde padrão que a maioria dos professores preferiu seguir tecnicamente, sem tentativas de ampliar suas possibilidades ou realizar modificações em seu roteiro ou construção. 
Em outras palavras, mesmo apresentando-lhes liberdade de escolha para a atividade experimental, identificamos em seus discursos um baixo nível de ações reveladoras de uma autonomia docente capaz de atribuir-lhes o modelo do "intelectual crítico", segundo a visão de Contreras (2002), embora tenhamos identificado alguns indícios para tal em poucos sujeitos analisados.

Vale destacar que as análises destes discursos permitiram emergir uma forte componente motivacional, proveniente de alguns indivíduos, especialmente nos casos de P9 e P2. Parece evidente o fato da influência significativa e relevante de sentimentos pessoais e emotivos quanto ao tema da Astronomia no processo de construção da autonomia docente para a realização criativa de ações adicionais às que o Projeto Eratóstenes sugeria. Como constatado nas análises anteriormente apresentadas, inferimos: a partir de moderadores discursivos relacionados à dimensão motivacional, o "amor" pela profissão e pelo tema de ensino contribuiu diretamente para o desenvolvimento profissional da autonomia, predominantemente presente em P9 e P2. Estes professores apresentaram fortes indícios de um profissional transformador devido à contribuição da intensa relação afetiva pela profissão e pelo tema "Astronomia". Uma antecipação discursiva nos permite questionar: estes professores teriam atingido este nível de autonomia se não apresentassem esta afetividade pela Astronomia? Por isso, uma componente emotiva parece estar diretamente relacionada ao processo do desenvolvimento da autonomia docente.

\section{Síntese dos resultados}

Apresentamos, a seguir, uma síntese categorizada a partir dos resultados encontrados quanto aos elementos que contribuem para a construção da autonomia docente na elaboração e execução de experimentos didáticos para o ensino de Astronomia sob a luz da fundamentação aqui comentada, isto é, a resposta à questão de pesquisa. Ao abordar cada um destes elementos, a Fig. 9 serviu de apoio argumentativo, conforme extraído dos estudos de Langhi e Nardi (2011).

- Elementos referentes ao modelo conteudista (características inerentes ao modelo: individualista, acrítico, impessoal, amplitude limitada de saberes, autonomia ilusória, profissional como especialista técnico e reprodutivista).

O professor deve reconhecer o uso equilibrado de fontes confiáveis de conteúdos para o ensino da Astronomia, sem, contudo, unificar o ensino sob o modelo exclusivamente conteudista, compreendendo o potencial dos resultados de pesquisas sobre Educação em Astronomia em contribuir com propostas de diferentes metodologias de ensino que utilizam atividades práticas diferenciadas, especialmente as que atendam o aspecto observacional da Astronomia, visando superar os limites da autonomia ilusória (no caso do Projeto Eratóstenes, a montagem do gnômon). 
- Elementos referentes ao modelo tecnicista (características inerentes ao modelo: individualista, acrítico, impessoal, amplitude limitada de saberes, autonomia ilusória, profissional como especialista técnico).

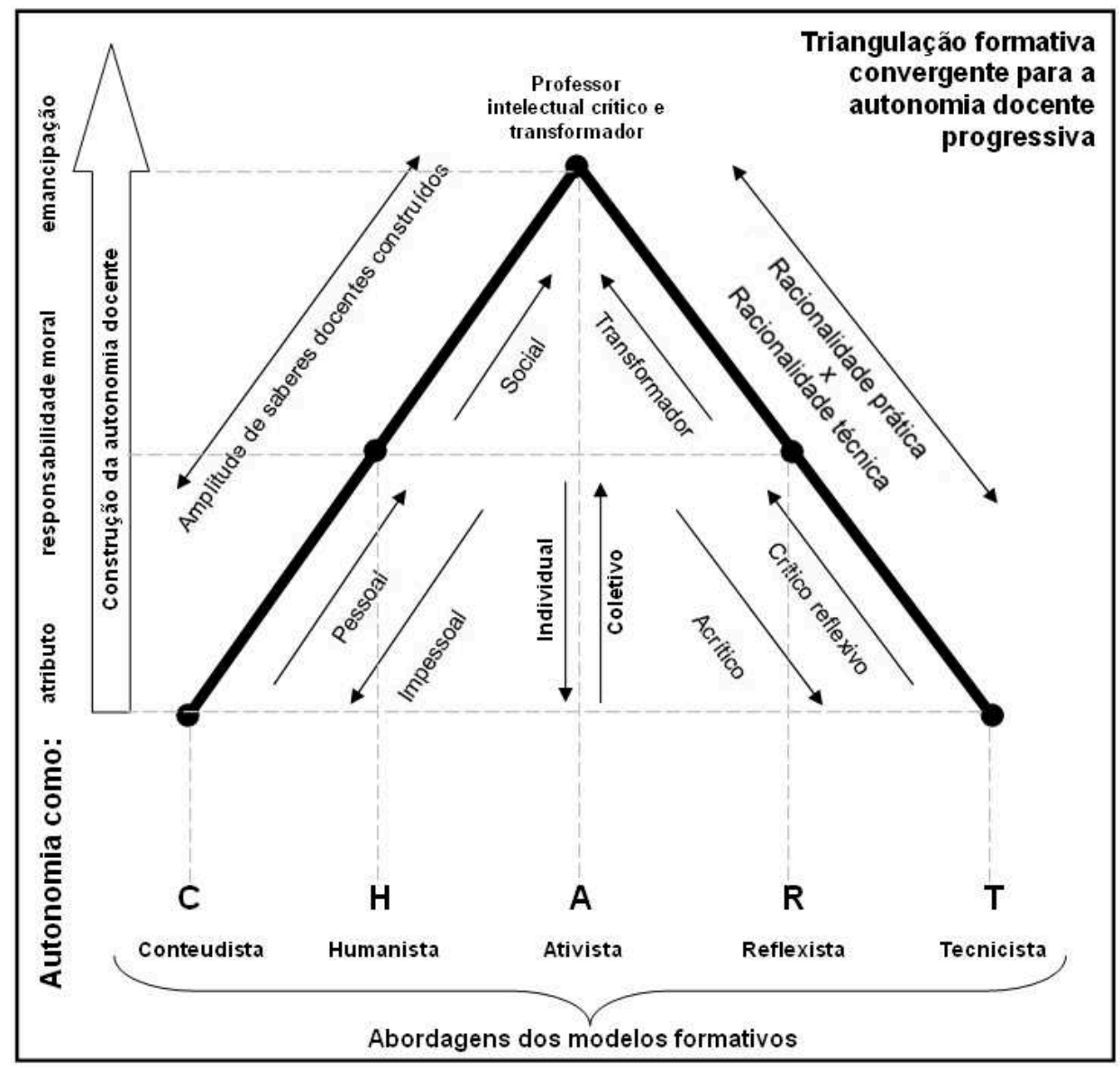

Fig. 9 - Dispositivo analítico de apoio (Fonte: LANGHI; NARDI, 2011).

Embora exista uma componente de racionalidade técnica desejável no ensino com atividades experimentais, não manter a pluralidade metodológica pode restringir o desenvolvimento da autonomia no trabalho do professor a uma dimensão acrítica, diante do modelo vigente por ele praticado, ou limitá-lo quanto à criatividade de manipulações diferenciadas no modelo experimental proposto para o trabalho com tópicos de Astronomia envolvendo marcações e medidas a partir da observação de um fenômeno (no caso do Projeto Eratóstenes, o movimento diurno aparente do Sol na esfera celeste).

- Elementos referentes ao modelo humanista (características inerentes ao modelo: mais coletivo, crítico, pessoal, conjunto de saberes docentes mais amplo, autonomia como responsabilidade moral própria, profissional mais reflexivo, fortes relações afetivas). 
O professor deve levar em conta os diferentes pontos de vista e os sentimentos pessoais despertados pelos aspectos motivacionais do tema Astronomia usando atividades práticas especialmente elaboradas com problemas abertos e roteiros semi ou não estruturados, visando o uso responsável da autonomia por meio de discussões entre seus executores para formulações de soluções quanto a possíveis erros de execução ou modificações do aparato experimental sugerido, as quais possam contribuir para o desenvolvimento de sentimentos inerentes do ser humano, tais como admiração, fascínio, interesse, curiosidade (no caso do Projeto Eratóstenes, o despertar da curiosidade e admiração pelo conhecimento historicamente construído acerca dos movimentos celestes).

- Elementos referentes aos saberes docentes (características inerentes ao modelo: mais coletivo, crítico, pessoal, saberes docentes mais constituídos, autonomia como responsabilidade moral própria, profissional reflexivo).

Se o professor favorece a construção de seus saberes docentes, numa maior amplitude e diversidade, seu leque de ações amplia-se no sentido de uma ação profissional cada vez mais autônoma. Os saberes apresentam-se como um dos caminhos para que o professor entenda o ensino contemplando as demais competências e conhecimentos específicos da área docente, além daquele que normalmente é considerado como sendo o mais importante: o saber disciplinar, ou o conhecimento dos conteúdos a serem ensinados, no nosso caso, Astronomia. Reconhecemos o lugar que este saber ocupa na educação, mas afirmamos que não deve ser o único a ser trabalhado em programas de formação continuada, pois, caso contrário, este modelo formativo não passaria da dimensão conteudista e impessoal, ausentando o ensino de atividades experimentais colaborativas (no caso do Projeto Eratóstenes, mobilizaram-se para esta amostra de sujeitos, os saberes do uso das TIC, interdisciplinaridade e abordagem da História e Filosofia da Ciência).

- Elementos referentes ao modelo reflexivo (características inerentes ao modelo: mais coletivo, crítico, pessoal, saberes docentes mais constituídos, autonomia como responsabilidade moral própria, profissional reflexivo).

Deve-se ampliar o poder crítico do professor por meio de reflexões coletivas sobre a sua prática docente com relação ao uso das atividades experimentais no ensino da Astronomia, visando contribuir para o desenvolvimento progressivo de sua autonomia sob a perspectiva da racionalidade prática, à medida que sente-se capaz de lidar com obstáculos de ordem extrínseca e os relacionados à sua limitada formação inicial em Astronomia e à infraestrutura impeditiva do ambiente de ensino para a realização de atividades observacionais (no caso do Projeto Eratóstenes, as reflexões entre os pares de escolas oportunizaram uma enriquecedora troca de experiências e possíveis resoluções de problemas relacionados ao experimento).

- Elementos referentes ao modelo transformador (características inerentes ao modelo: coletivo, transformador, social, saberes docentes com amplitude, autonomia como emancipação, profissional intelectual crítico). 
Propõe-se ampliar as reflexões ao ponto de despertar no professor uma atitude transformadora e ativista em favor de mudanças em sua própria prática e da sociedade em que vive, utilizando-se de argumentos estáveis e plausíveis, cuja base apoia-se principalmente em resultados de pesquisas e investigações da área. Trata-se de um processo coletivo e não se resume no individualismo, pois o professor dependerá de apoio externo quanto ao amadurecimento de sua profissionalidade, tais como os ambientes não formais de ensino de Astronomia ou instituições e universidades que oferecem programas de formação continuada. Ao refletir e analisarse criticamente, o professor pode acarretar alterações em sua prática de ensino com relação ao uso de atividades experimentais em Astronomia, capacitando-o a atuar como autor e pesquisador, deixando-se influenciar pela pesquisa e influenciando-a (no caso do Projeto Eratóstenes, constatamos apenas indícios para transformações desta natureza).

\section{Considerações finais}

Os resultados deste estudo apresentam indicadores que nos levam a repensar no modo como compreendemos a formação de professores e o conceito de autonomia docente no que se refere à elaboração de atividades práticas para o ensino de Ciências, abrindo um lastro de potenciais pesquisas a esse respeito, pois os professores em exercício, de um modo geral, parecem não estar preparados para a autonomia profissional, descrita pela fundamentação aqui utilizada.

Ações como a descrita aqui potencializam a coleta de dados com rico valor investigativo para a área de Pesquisa em Ensino de Ciências. O Projeto Eratóstenes Brasil permanece aberto para socializar os dados que, eventualmente, possam ser constituídos a partir de suas atividades por quaisquer pesquisadores interessados a realizar estudos desta natureza. Além de uma preocupação quantitativa, contemplamos a importância da componente qualitativa na análise desses dados, uma vez que tais atividades nos proporcionam um grande volume de informações.

Críticas, sugestões, observações, relatos, dificuldades e pareceres dos professores participantes constituem-se em importante retorno para a reconstrução destes episódios formativos, no sentido de direcionar o trabalho da coordenação e atender às reais necessidades formativas deles. Ao preparar o material orientador para cada ano, fundamentado nos comentários dos professores e nos resultados das pesquisas, evidenciamos a relevância da sua leitura pelos participantes, pois contém informações que visam minimizar a propagação de erros conceituais e concepções alternativas em Astronomia.

$\mathrm{O}$ atual entendimento destes conceitos da parte de vários professores, bem como alguns receios em participar dessas ações nacionais indicam a necessidade da continuidade de uma formação docente voltada para a construção de sua autonomia e de seu desenvolvimento profissional em relação a uma maior segurança para o ensino de tópicos de Astronomia, sob modelos formativos que superem a abordagem exclusivamente conteudista e tecnicista, mas que levem em conta a importante componente reflexista e crítico-ativista, bem como o âmbito 
motivacional e sentimental que pode ser despertado. Portanto, acreditamos que a interação frequente dos professores em atividades desta natureza pode motivar outros profissionais a perceber a importância da Educação em Astronomia, como bem documentado na literatura da área.

\section{Referências}

ALMEIDA, T. R.; LANGHI, R. Projeto Eratóstenes Brasil: ensinando astronomia com autonomia. Simpósio Nacional de Ensino de Física, 19, Manaus, 2011. Anais... Manaus: SBF, 2011.

ALMEIDA, T. R.; LANGHI, R. Educação em Astronomia: autonomia docente em atividades experimentais através da formação continuada de professores. In: SIMPÓSIO NACIONAL DE EDUCAÇÃO EM ASTRONOMIA, 1, Rio de Janeiro, 2011. Anais... Rio de Janeiro: SAB, 2011a.

ARAÚJO, M. S. T.; ABIB, M. L. V. S. Atividades experimentais no ensino de Física: Diferentes enfoques, diferentes finalidades. Revista Brasileira de Ensino de Física, v. 25, n. 2, p. 176194, Jun.2003.

BARbosA, A. C. C.; CARVAlHAES, C. G.; COSTA, M. V. T. A computação numérica como ferramenta para o professor de Física do Ensino Médio. Revista Brasileira de Ensino de Física, v. 28, n. 2, p. 249-254, 2006.

BAROLLI, E. Reflexões sobre o Trabalho dos Estudantes no Laboratório Didático. 1998. 232 f. Tese (Doutorado em Educação) - USP, São Paulo.

BARROS S. G. La Astronomía en textos escolares de educación primaria. Enseñanza de las Ciencias, v. 15, n. 2, p. 225-232, 1997.

BEKERIS, V. et al. Eratosthenes 2009/2010: An old experiment in Modern Times. Astronomy Education Review, 10, 010201-1, 10.3847/AER2011007. 2011.

BEKERIS, V. et al. O Projeto Eratóstenes versão 2012: resultados. Disponível em: <http://difusion.df.uba.ar>. Acesso em: jan 2012.

BOCZKO, R. Conceitos de astronomia. São Paulo: Blucher, 1984.

BOGDAN, R. C.; BIKLEN, S. K. Investigação qualitativa em educação. Portugal: Porto Editora, 1994.

BORGES, A. T. Novos rumos para o laboratório escolar de Ciências. Caderno Brasileiro de Ensino de Física, v. 19, n. 3, p. 291-313, dez. 2002.

BORGES, A. T.; BORGES, O.; VAZ, A. Os planos dos estudantes para resolver problemas práticos. Revista Brasileira de Ensino de Física, v. 27, n. 3, p. 435-446, 2005. 
BOZIC, M.; DUCLOY, M. Eratosthenes' teachings with a globe in a school yard. Physics Education, v. 43, n. 2, p. 165-172, 2008.

BRANDÃO, H. H. N. Introdução à análise do discurso. 8. ed. São Paulo: Editora da UNICAMP, 2002.

BRASIL. Secretaria de Educação Média e Tecnologia. Parâmetros Curriculares Nacionais: ciências naturais. Brasília: MEC/SEMTEC, 1997.

BRASIL. Secretaria de Educação Média e Tecnologia. Parâmetros Curriculares Nacionais: terceiro e quarto ciclos do ensino fundamental - ciências naturais. Brasília: MEC/SEMTEC, 1998.

BRETONES, P. S. Disciplinas introdutórias de Astronomia nos cursos superiores do Brasil. 1999. Dissertação (Mestrado) - Instituto de Geociências, UNICAMP.

CAMINO, N. Ideas previas y cambio conceptual en Astronomía. Un estudio con maestros de primaria sobre el día y la noche, las estaciones y las fases de la luna. Enseñanza de las Ciencias, v. 13, n. 1, p. 81-96, 1995.

CAMINO, N. Aprender a imaginar para comenzar a comprender: Los "modelos concretos" como herramientas para el aprendizaje en astronomía. Revista Alambique, v. 42 [Versión electrónica], 2004.

CAMINO, N. et al. Ensino de Astronomia: ação conjunta de observação do equinócio de março. Projeto CTS 4 Astronomia Guia Didático. Cadernos SBPC, n. 31, jun 2009.

CANALLE, J. B. G.; TREVISAN, R. H.; LATTARI, C. J. B. Análise do conteúdo de Astronomia de livros de geografia de $1^{\circ}$ grau. Caderno Catarinense de Ensino de Física, v. 14, n. 3 , p. 254-263, 1997.

CASARIN, A. T.; ALMEIDA, T. R.; CORRÊA, H. P. S.; CORVALAN, A. R.; LANGHI, R.; MARTINS, K. C. O.; PEDROZO JUNIOR, V. R. Projeto Eratóstenes Brasil. Seminário de Extensão Universitária da Região Centro-Oeste, 5, Goiânia, 2012. Anais... Goiânia: UFG, 2012.

CONTRERAS, J. A autonomia de professores. São Paulo: Cortez, 2002.

DAMÁSIO, F.; STEFFANI, M. H. Ensinando física com consciência ecológica e com materiais descartáveis. Revista Brasileira de Ensino de Física, v. 29, n. 4, p. 593-597, 2007.

DILLER, A. The Ancient Measurements of the Earth. Isis, v.40, n.1, p.6-9, fev. 1949.

DRABKIN, I. E. Posidonius and the Circumference of the Earth. Isis, v. 34, n. 6, p. 509-512, 1943. 
ENGELS, D. The Length of Eratosthenes' Stade. The American Journal of Philology, v. 106, n. 3, p. 298-311, 1985.

FERREIRA, F. P.; HENRIQUE, A. B. Potencialidades de experimentos históricos no ensino das Ciências: o caso da medida do raio da Terra realizada por Eratóstenes. In: ENCONTRO NACIONAL DE PESQUISADORES EM HISTÓRIA DAS CIÊNCIAS, 2, Salvador, 2011. Caderno de Resumos e Programação das Atividades... Salvador, ENPHC, 2011.

FLICK, U. Introdução à pesquisa qualitativa. Porto Alegre: Artmed, 2009.

GATTI, S. R. T.; NARDI, R. Análise de práticas pedagógicas realizadas em atividades de formação continuada de professores: a aproximação da História e Filosofia da Ciência no ensino de Física. In: NARDI, R. (Org). Ensino de Ciências e Matemática: temas sobre a formação de professores. São Paulo: UNESP Cultura Acadêmica, 2009.

GAUTHIER, C. et al. Por uma teoria da pedagogia: pesquisas contemporâneas sobre o saber docente. Ijuí/BRA: Editora UNIJUI, 1998.

GIL, A. C. Como elaborar projetos de pesquisa. 3. ed. São Paulo: Atlas, 1996.

GIOPPO, C.; SCHEFFER, E. W. O.; NEVES, M. C. D. O ensino experimental na escola fundamental: uma reflexão de caso no Paraná. Educar em Revista, n. 14, p. 39-57, 1998.

GIROUX, H. A. Os professores como intelectuais: rumo a uma pedagogia crítica da aprendizagem. Porto Alegre: Atmed, 1997.

GOLDENBERG, M. A arte de pesquisar: como fazer pesquisa qualitativa em Ciências Sociais. 5. ed. Rio de Janeiro: Record, 2001.

HECKLER, V., SARAIVA, M. F. O.; OLIVEIRA FILHO, K. S. Uso de simuladores, imagens e animações como ferramentas auxiliares no ensino/aprendizagem de óptica. Revista Brasileira de Ensino de Física, v. 29, n. 2, p. 267-273, 2007.

HODSON, D. Hacia un enfoque más crítico del trabajo de laboratorio. Enseñanza de las Ciencias, v. 12, p. 299-313, 1994.

LANGHI, R. Um estudo exploratório para a inserção da Astronomia na formação de professores dos anos iniciais do Ensino Fundamental. 2004. Dissertação (Mestrado em Educação para a Ciência) - Faculdade de Ciências, UNESP, Bauru.

LANGHI, R. Um levantamento bibliográfico das idéias de senso comum de alunos e professores sobre fenômenos astronômicos. In: IAG/USP. Projeto Observatórios Virtuais. São Paulo: 2005. CD-ROM. 
LANGHI, R. Astronomia nos anos iniciais do ensino fundamental: repensando a formação de professores. 2009. 370 f. Tese (Doutorado em Educação para a Ciência) - Faculdade de Ciências, UNESP, Bauru.

LANGHI, R. Aprendendo a ler o céu: pequeno guia prático para a astronomia observacional. Campo Grande: Ed. UFMS, 2011.

LANGHI, R. Projeto Eratóstenes Brasil. Revista Planetaria, v. 1, n. 3, p. 15-17, set. 2014.

LANGHI, R.; MACHADO, T. Projeto Eratóstenes Brasil. In: FÓRUM DE EXTENSÃO UNIVERSITÁrIA, 3, 2013, Bauru. Anais... São Paulo: UNESP, 2013.

LANGHI, R.; MARTINS, B. A. Um estudo exploratório sobre os aspectos motivacionais de uma atividade não escolar para o ensino da Astronomia. In: SIMPÓSIO NACIONAL DE EDUCAÇÃo EM ASTRONOMIA, 3, 2014, Curitiba. Atas... São Paulo: SAB, 2014.

LANGHI, R.; NARDI, R. Ensino de Astronomia: erros conceituais mais comuns presentes em livros didáticos de ciências. Caderno Brasileiro de Ensino de Física, v. 24, n. 1, p. 87-111, abr. 2007.

LANGHI, R.; NARDI, R. Astronomia nos anos iniciais do Ensino Fundamental: interpretação das expectativas e dificuldades presentes em discursos de professores. Revista de Enseñanza de la Física, v. 20, p. 17-32, 2007a.

LANGHI, R.; NARDI, R. Interpretando reflexões de futuros professores de física sobre sua prática profissional durante a formação inicial: a busca pela construção da autonomia docente. Investigações em Ensino de Ciências, Porto Alegre, v. 16, n. 3, p. 403-424, 2011.

LANGHI, R.; NARDI, R. Educação em Astronomia: repensando a formação de professores. São Paulo: Escrituras, 2012.

LANGHI, R.; NARDI, R. Justificativas para o ensino de Astronomia: o que dizem os pesquisadores brasileiros? Revista Brasileira de Pesquisa em Educação em Ciências, v. 14, n. 3, p. 41-59, 2014.

LANGHI, R.; PEDROZO JUNIOR, V. R.; MARTINS, K. C. O. À procura de características de ações nacionais para a Educação em Astronomia. In: SIMPÓSIO NACIONAL DE EDUCAÇÃO EM ASTRONOMIA, 2, 2012, São Paulo. Atas... São Paulo: USP, 2012.

LANGHI, R.; VILAÇA, J. Brazilian Eratosthenes Project. In: LATIN AMERICAN REGIONAL IAU MEETING, 14, Florianópolis, 2013. Abstract book... Florianópolis: SAB, 2013. 
LANGHI, R.; SCALVI, R. M. F.; VILAÇA, J. Educação em Astronomia no Brasil: fundamentando propostas de ações nacionais. In: ENCONTRO NACIONAL DE PESQUISA EM EDUCAÇÃO EM CIÊNCIAS, 9, 2013, São Paulo, 2. Atas... Águas de Lindóia: ABRAPEC, 2013.

LASKY, K. O Bibliotecário que Mediu a Terra. Rio de Janeiro: Salamandra, 2000.

LONGHINI, M. D.; SILVESTRE, R. F.; VIEIRA, F. C. F. Uma estratégia para a construção de um rosa dos ventos envolvendo geometria, arte, astronomia e tecnologia. Física na Escola, v. 1, n. 1, 2010.

LOPES, M. H. O. A retrogradação dos planetas e suas explicações: os orbes dos planetas e seus movimentos, da antiguidade a Copérnico. 2001. 245f. Dissertação (Mestrado em História da Ciência) - PUC-SP, São Paulo.

MACHADO, T.; LANGHI, R. Desafios curriculares na Educação em Astronomia e a formação de professores: um levantamento bibliográfico. In: CONGRESSO BRASILEIRO DE EDUCAÇÃO, 4, 2013, São Paulo. Atas... São Paulo: UNESP, 2013.

MALUF, V. J. A Terra no espaço: a desconstrução do objeto real na construção do objeto cientifico. 2000. Dissertação (Mestrado) - Instituto de Educação, Univ. Fed. de Mato Grosso.

MARINELI, F.; PACCA, J. L. A. Uma interpretação para dificuldades enfrentadas pelos estudantes em um laboratório didático de Física. Revista Brasileira de Ensino de Física, v. 28, n. 4, p. 497-505, 2006.

MATTHEWS, M. R. Historia, Filosofia e Enseñanza de las Ciencias: la aproximación actual. Revista de las Ciencias, v. 12, n. 2, p. 255-271, 1994.

MORAES, R. O significado da experimentação numa abordagem construtivista: O caso do ensino de ciências. In: BORGES, R. M. R.; MORAES, R. (Org.) Educação em Ciências nas séries iniciais. Porto Alegre:Sagra Luzzato, 1998.

MOURÃO, R. R. F. Dicionário enciclopédico de astronomia e astronáutica. Rio de Janeiro: Nova Fronteira, 1987.

NARDI, R. Um estudo psicogenético das ideias que evoluem para a noção de campo subsídios para a construção do ensino desse conceito. 1989. Tese (Doutorado em Educação)Faculdade de Educação, Universidade de São Paulo.

NARDI, R. Memórias da educação em ciências no Brasil: a pesquisa em Ensino de Física. Investigações em Ensino de Ciências, v. 10, n. 1, p. 63-101, 2005.

NUNES, P. Estudantes vão determinar o raio da Terra. Scientific American Brasil, v. 11, n. 123, p. 15, ago 2012. 
ON. Observatório Nacional. Divisão Serviço da Hora (DSHO). Disponível em: <http://www.horalegalbrasil.mct.on.br/>. Acesso em: jul. 2016.

ORLANDI, E. P. Discurso e leitura. 8. ed. São Paulo: Cortez, 2000.

ORLANDI, E. P. Análise de discurso: princípios e procedimentos. 4. ed. São Paulo: Pontes, 2002.

PEB. Projeto Eratóstenes Brasil. Disponível em:<http://sites.google.com/site/projetoerato>. Acesso em: jul 2016.

PEREIRA, P. C. R. et al. Revivendo Eratóstenes: o amadurecimento de uma atividade educaional. In: REUNIÃO DA SOCIEDADE ASTRONÔMICA BRASILEIRA, 31, 2006, Águas de Lindóia. Anais... São Paulo: SAB, 2006.

PEREIRA, P. C. R. Revivendo Eratóstenes. Revista Latino-Americana de Educação em Astronomia, n. 3, p. 19-38, 2006.

PÉREZ, M. L. D. Historia y filosofía de las ciencias para qué? Entrevista a Jean Gayon. Ciencia Ergo Sum, v. 12, n. 3, 2005.

PRETTO, N. L. A ciência dos livros didáticos. Campinas: Unicamp, 1985.

QUINTANILLA, M.; IZQUIERDO, M.; ADÚRIZ-BRAVO, A. Avances en la construcción de marcos teóricos para incorporar la historia de la ciencia en la formación inicial del professorado de ciencias naturales. Enseñanza de las Ciencias, número extra, VII Congreso, 2005.

RABONI, P. C. A. Atividades práticas de ciências naturais na formação de professores para as series iniciais. 2002. 166f. Tese (Doutorado em Educação) - Unicamp, Campinas.

SANTOS, A. J. J. et al. O Projeto Eratóstenes: a reprodução de um experimento histórico como recurso para a inserção de conceitos da Astronomia no Ensino Médio. Caderno Brasileiro de Ensino de Física, v. 29, n. 3, p. 1137-1174, dez. 2012.

SANTOS, E. I.; PIASSI, L. P. C.; FERREIRA, N. C. Atividades experimentais de baixo custo como estratégia de construção da autonomia de professores de Física: uma experiência em formação continuada. In: ENCONTRO NACIONAL DE PESQUISA EM ENSINO DE FÍSICA, 9, 2004, Jaboticatubas. Anais... Minas Gerais: SBF, 2004.

SHEN, J.; CONFREY, J. From Conceptual change to transformative modeling: A case study of an elementary teacher in learning Astronomy. Science Education, p. 948-966, jan. 2007. DOI $10.1002 /$ sce.

TARDIF, M. Saberes docentes e formação profissional. 4. ed. Petrópolis: Vozes, 2004. 
TIGNANELLI, H. L. Sobre o ensino da astronomia no ensino fundamental. In: WEISSMANN, H. (org.). Didática das ciências naturais: contribuições e reflexões. Porto Alegre: Artmed, 1998.

TREVISAN, R. H. et al. Assessoria na avaliação do conteúdo de Astronomia dos livros de ciências do primeiro grau. Caderno Catarinense de Ensino de Física, v. 14, n. 1, p. 7-16, 1997.

ZEICHNER, K. A formação reflexiva de professores: ideias e práticas. Lisboa: EDUCA, 1993.

ZEILIK, M. Astronomy: the evolving universe. 9. ed. USA: Cambridge University Press, 2003. 